Research Paper

\title{
Liver Function Parameters in Hip Fracture Patients: Relations to Age, Adipokines, Comorbidities and Outcomes
}

\author{
Leon Fisher1, Wichat Srikusalanukul², Alexander Fisher ${ }^{2,4}{ }^{\bowtie}$ and Paul Smith ${ }^{3,4}$ \\ 1. Department of Gastroenterology, The Canberra Hospital, Canberra, ACT, Australia \\ 2. Department of Geriatric Medicine, The Canberra Hospital, Canberra, ACT, Australia \\ 3. Department of Orthopaedic Surgery, The Canberra Hospital, Canberra, ACT, Australia \\ 4. Australian National University Medical School, Canberra, ACT, Australia
}

$\bowtie$ Corresponding author: Alex.Fisher@act.gov.au

( ) Ivyspring International Publisher. This is an open-access article distributed under the terms of the Creative Commons License (http://creativecommons.org/ licenses/by-nc-nd/3.0/). Reproduction is permitted for personal, noncommercial use, provided that the article is in whole, unmodified, and properly cited.

Received: 2014.01.03; Accepted: 2014.04.11; Published: 2015.01.01

\begin{abstract}
Aim: To asses liver markers in older patients with hip fracture (HF) in relation to age, comorbidities, metabolic characteristics and short-term outcomes.

Methods: In 294 patients with HF (mean age $82.0 \pm 7.9$ years, $72.1 \%$ women) serum alanine aminotransferase (ALT), gammaglutamyltransferase (GGT), alkaline phosphatase (ALP), albumin, bilirubin, $25(\mathrm{OH})$ vitaminD, PTH, calcium, phosphate, magnesium, adiponectin, leptin, resistin, thyroid function and cardiac troponin I were measured.

Results: Elevated ALT, GGT, ALP or bilirubin levels on admission were observed in $1.7 \%-9.9 \%$ of patients. With age GGT, ALT and leptin decrease, while PTH and adiponectin concentrations increase. Higher GGT (>30U/L, median level) was associated with coronary artery disease (CAD), diabetes mellitus (DM), and alcohol overuse; lower ALT ( $\leq 20 \mathrm{U} / \mathrm{L}$, median level) with dementia; total bilirubin $>20 \mu \mathrm{mol} / \mathrm{L}$ with CAD and alcohol overuse; and albumin $>33 \mathrm{~g} / \mathrm{L}$ with CAD. Multivariate adjusted regression analyses revealed ALT, ALP, adiponectin, alcohol overuse and DM as independent and significant determinants of GGT (as continuous or categorical variable); GGT for each other liver marker; and PTH for adiponectin. The risk of prolonged hospital stay ( $>20$ days) was about two times higher in patients with GGT>30U/L or adiponectin $>17.14 \mathrm{ng} / \mathrm{L}$ (median level) and 4.7 times higher if both conditions coexisted. The risk of in-hospital death was 3 times higher if albumin was $<33 \mathrm{~g} / \mathrm{L}$.

Conclusions: In older HF patients liver markers even within the normal range are associated with age-related disorders and outcomes. Adiponectin (but not $25(\mathrm{OH})$ vitaminD, PTH, leptin or resistin) is an independent contributor to higher GGT. Serum GGT and albumin predict prolonged hospital stay and in-hospital death, respectively. A unifying hypothesis of the findings presented.
\end{abstract}

Key words: liver function, adipokines, hip fracture, comorbidities, outcomes

\section{Introduction}

Global population ages rapidly, and by the year 2050 the percentage of people $>60$ years of age is expected to reach $22 \%$. Advanced age is the single major independent risk factor for most chronic diseases and functional deficits, accounting for $60 \%$ of all deaths worldwide. The liver because of its multitude metabolic, homeostatic and detoxification functions plays a central role in aging and susceptibility to age-related diseases. Ageing is associated with significant loss of hepatic volume and blood flow, structural changes in 
all liver cells, accumulation of ageing pigments at the cytoplasm and pseudocapillarization of the sinusoid. ${ }^{1-4}$ Over the past several years, substantial research has shown that alanine aminotransferase (ALT) and gamma-glutamyltransferase (GGT) activities decrease with old age. ${ }^{5-10}$ However, the relationship between ageing and liver function and diseases remains obscure. ${ }^{11}$ For example, a number of reports concluded that in the elderly low ALT level is a strong and independent predictor of mortality, ${ }^{6,8,12-15}$ while in other studies of community-dwelling older adults ${ }^{14}$, 16-18 and older twins, ${ }^{19}$ elevated serum ALT,16 aspartate aminotransferase (AST), alkaline phosphatise $(\mathrm{ALP})^{14,17,20}$ and, especially, GGT levels ${ }^{12}$, 14, 18, 20-29 predicted all-cause, cardiovascular, and liver mortality.

Numerous investigators found a positive association between ALT and/or GGT activities and metabolic syndrome, non-alcoholic fatty liver disease, type 2 diabetes mellitus (DM), cardiovascular disease (CVD), including coronary artery disease (CAD), hypertension, heart failure and stroke, chronic kidney disease, and cancers, ${ }^{19}, 27,30-44$ conditions which are highly prevalent in older individuals. The aforementioned associations were often evident across ALT and GGT activities values within the normal range, ${ }^{13}$, $21,23,31,45-47$ independent of alcohol intake and other risk factors. Notably, although most of these studies did not focus specifically on the elderly population and the results have not been entirely consistent, ${ }^{48}$ these associations were strong in young individuals, but weakened with age. $21,22,24,36,42,49,50$

Liver is critically involved in metabolism of many factors contributing to bone health and hepatic osteodystrophy is a common well-documented complication in patients with chronic liver disease. ${ }^{51-58}$ Surprisingly, limited research has examined the liver function in older patients with hip fracture (HF).59, 60 Liver markers, except low serum albumin concentration for mortality $61-68$ and increased postoperative complications, ${ }^{61,69}$ are not currently included in the prognostic criteria.

The potential pathogenic role of factors affecting both liver and bone, such as low vitamin D status, elevated PTH levels, dysregulation in secretion of adipokines (especially, adiponectin, leptin and resistin), all of which are common in the elderly, virtually have not been investigated systematically in HF patients, despite growing evidence that the liver, the bone and adipose tissue are functionally interrelated organs. ${ }^{70}$ The aforementioned metabolic mechanisms are important for optimal function of many organs and tissues throughout the body and involved in numerous age-related comorbidities which may substantially contribute to poor outcomes in HF patients.
To our knowledge, no published study has evaluated the relationship between liver function parameters and age, comorbidities, adipokines, vitamin $\mathrm{D}$ and PTH, as well as short-term outcomes in HF patients.

The aim of this prospective observational study was three-fold: 1) to determine liver function parameters in older HF patients in relation to age, and whether markers of hepatic function are associated with comorbidities, 2) to evaluate the relationship between serum liver markers, on one hand, and serum concentrations of vitamin $\mathrm{D}, \mathrm{PTH}$, adipokines adiponectin, leptin, and resistin, on the other, and 3) to assess the value of liver function markers on admission as predictors of short-term outcomes.

\section{Materials and Methods}

\section{Patients}

The study population consisted of 294 patients (212 females and 82 males) aged 60 years and older with low-trauma osteoporotic HF admitted to The Canberra Hospital. Patients with high trauma, pathological HF, Paget's disease, primary hyperparathyroidism or who did not have all serum variables of interest measured were not considered for the study. A detailed medical history, full physical examination and medication use were obtained along with demographic and anthropometric variables in all patients.

Informed consent was obtained from all individuals or their carers. The study was approved by the regional ACT Health Human Research Ethical Committee and conducted according to the Helsinki Declaration (as revised in 2008).

\section{Laboratory Analyses}

After 12-hour overnight fast usually within 24 hours after arrival at the Emergency Department venous blood samples were taken and sera were isolated. One serum sample was frozen and stored at $-70^{\circ} \mathrm{C}$ until further analysis of adiponectin, leptin and resistin. All other haematological and biochemical assessments were performed at the day of collection. All patients had the following tests performed: liver function markers (ALT, GGT, ALP, albumin and total bilirubin), complete blood count, urea, creatinine and electrolytes, fasting blood glucose (and HbA1C in diabetic patients), thyroid function tests (TSH, T4 and $\mathrm{T} 3$ if indicated), $25(\mathrm{OH})$ vitamin $\mathrm{D}[25(\mathrm{OH}) \mathrm{D}]$, intact $\mathrm{PTH}$, total calcium, phosphate, magnesium, C-reactive protein (CRP) and cardiac troponin I (cTnI), adiponectin, leptin and resistin.

Liver function tests were evaluated by using commercially available standard enzymatic reagents and diagnostic kits by spectrophotometry on the bio- 
chemical autoanalyzer Abbott Architect CI16200 (Abbott Laboratories, IL 60064, USA). ALT, GGT and ALP were measured with enzymatic colorimetric methods, total bilirubin was analysed using diazonium salt, total protein was tested by a Biuret method and albumin was measured using bromcresol green. The mean inter-assay and intra-assay coefficients of variations $(\mathrm{CV})$ for these tests were within $1.1 \%$ $6.6 \%$.

Serum levels of leptin were determined by enzyme-linked immunosorbent assay (ELISA) method (Diagnostic System Laboratories, Webster, TX, USA), total adiponectin and resistin by human ELISA kits (B-Bridge International, Mountain View, CA, USA). Intra- and interassay $\mathrm{CV}$ were less than $7 \%$ for these tests. All assays were performed according to the manufactures' instructions with kits of the same lot number.

Serum levels of $25(\mathrm{OH}) \mathrm{D}$ were determined by a radioimmunoassay kit (Dia Sorin, Stillwater, $\mathrm{MN}$, USA; interassay CV 5.9-9.4\%, intraassay CV $<11.5 \%$ ), intact PTH by solid-phase two-site chemiluminescent enzyme-linked immunometric assay on a DPC Immulite 2000 analyzer (Diagnostic Products, Los Angeles, CA, USA; interassay CV 6.2-7.0\%, intraassay $\mathrm{CV}<6 \%$ ), cTnI by two-step chemiluminescent microparticle immunoassay (Chemiflex, Abbott Labs, Mississauga, Ontario, Canada; the minimum detectable limit $0.03 \mu \mathrm{g} / \mathrm{L}$ and the upper limit of reference range is $0.06 \mu \mathrm{g} / \mathrm{L})$. Serum calcium concentration was corrected for serum albumin. Glomerular filtration rate (eGFR) was estimated using a standardized serum creatinine-based formula normalized to a body surface area of $1.73 \mathrm{~m}^{2}$ (Levey A 2010; Johnson D 2012). All serum samples were processed in the same laboratory using the same methods and the same reference values.

For liver enzymes 2 times the upper normal limit (UNL) cut-off levels were used to define abnormal tests. When aminotransferase activities were analysed as categorical variables median values were used: for ALT 20U/L and for GGT 30U/L, levels comparable with data in the literature (Ruhl C 2012; Wu W 2012).

For the analyses, insufficiency of vitamin $\mathrm{D}$ was defined as $25(\mathrm{OH}) \mathrm{D}<50 \mathrm{nmol} / 1$ and deficiency as $25(\mathrm{OH}) \mathrm{D}<25 \mathrm{nmol} / 1$ based on current recommendations. Secondary hyperparathyroidism (SHPT) was defined as elevated serum PTH ( $>6.8 \mathrm{pmol} / 1$, the upper limit of the laboratory reference range).

Short-term outcomes included in-hospital all-cause mortality, prolonged length of stay $(>20$ days), post-operative myocardial injury defined by cardiac troponin I rise $(>0.06 \mu \mathrm{g} / \mathrm{L})$, high inflammatory response (CRP>100 mg/L) and being discharged to a permanent residential care facility.

\section{Statistical Analyses}

Statistical calculations were carried out using the Stata software version 10 (StataCorp, College Station, TX, USA). The summary statistics are presented as the mean \pm standard deviation (SD) for continuous variables and as the number (percentages) for categorical variables. Comparisons between groups of patients were made by use Student's $t$ test for normally distributed continuous variables and a $\chi^{2}$ test for categorical variables. The relationships between variables were examined by Pearson's linear correlation test and multivariate logistic regression analyses after logarithmic transformation of continuous variables with a skewed distribution. When the dependent parameter was stratified by level to further assess the independent participation of each of the factors studied, odds ratios with 95\% confidence intervals (CI) were measured in multivariate logistic regression models, incorporating into the models biomarkers as continuous variables and clinical characteristics (sex, presence of CVD, DM, excessive alcohol consumption, history of smoking, etc) as categorical/ binary variables (yes, no). Bonferroni and Sidak adjustments for multiplicity were performed. To assess the significance of multicollinearity phenomena in multivariate regression analyses, the variance inflation factor was calculated. Results were considered statistically significant if $P$ values $<0.05$ (two-sided).

\section{Results}

\section{Characteristics of patients}

Demographic, biochemical and haematological characteristics of the study population on admission are summarized in Table 1 . The mean age of the patients was 82.0 years, $72.1 \%$ were women who were slightly older than men $(+2.0$ years, $\mathrm{p}=0.053)$, and $89(30.2 \%)$ subjects were admitted from long care residential facilities. There were 152 patients with a cervical HF and 142 with an intertrochanteric HF. The prevalent comorbidities at the time of hospitalisation for HF included CVD (66.3\%), chronic kidney disease (CKD) $\geq$ stage 3 (eGFR $\left.<60 \mathrm{ml} / \mathrm{min} / 1.73 \mathrm{~m}^{2}, 43.2 \%\right)$, dementia $(27.8 \%)$, history of stroke or transient ischaemic attack $(19.7 \%)$, type 2 DM $(16.4 \%)$, chronic obstructive pulmonary disease (COPD, 11.0\% ), and Parkinson's disease $(4.6 \%) ; 28(9.5 \%)$ patients consumed alcohol 3 or more times a week. In the study population $51(17.3 \%)$ of patients had neither CVD, CKD, or DM, nor were alcohol overusers. The prevalence of abnormal liver tests was as follows: ALT $(>2 \mathrm{ULN}, 80 \mathrm{U} / \mathrm{L})$ in $5(1.7 \%)$ patients, GGT (>2ULN, $128 \mathrm{U} / \mathrm{L})$ in $23(7.8 \%)$, ALP (>2ULN, $120 \mathrm{U} / \mathrm{L})$ in 26 $(8.8 \%)$, bilirubin ( $>1 \mathrm{ULN}, 20 \mu \mathrm{mol} / \mathrm{L})$ in $29(9.9 \%)$ and albumin $(<33 \mathrm{~g} / \mathrm{L})$ in $64(21.8 \%)$ subjects. The liver 
function abnormalities were small in magnitude and not associated with clinically apparent hepatic disease. There were no gender differences in indicators of liver functions, haemoglobin, and glycosylated haemoglobin (HbA1c) values. However, women, compared to men, had higher PTH, leptin, adiponectin and T4 concentrations and significantly lower mean $25(\mathrm{OH}) \mathrm{D}$ and eGFR levels.

Table 1. General characteristics of patients with hip fractures by gender

\begin{tabular}{|c|c|c|c|c|}
\hline & $\begin{array}{l}\text { Total Sample } \\
(\mathrm{n}=294)\end{array}$ & $\begin{array}{l}\text { Men } \\
(n=82)\end{array}$ & $\begin{array}{l}\text { Women } \\
(\mathrm{n}=212)\end{array}$ & $\begin{array}{l}\mathrm{P} \\
\text { Value }\end{array}$ \\
\hline Age, years & $82.0 \pm 7.9$ & $80.6 \pm 8.3$ & $82.6 \pm 7.7$ & 0.053 \\
\hline $\begin{array}{l}\text { Cervical/Trochanteric } \\
\text { fracture, } \mathrm{n}\end{array}$ & $152 / 142$ & $38 / 44$ & $114 / 98$ & 0.298 \\
\hline GGT, U/L & $54.1 \pm 95.6$ & $57.9 \pm 106.0$ & $52.6 \pm 91.5$ & 0.670 \\
\hline $\mathrm{ALT}, \mathrm{U} / \mathrm{L}$ & $23.0 \pm 42.6$ & $18.9 \pm 11.1$ & $24.6 \pm 49.6$ & 0.302 \\
\hline $\mathrm{ALP}, \mathrm{U} / \mathrm{L}$ & $105.4 \pm 80.1$ & $98.6 \pm 64.6$ & $108.2 \pm 85.3$ & 0.343 \\
\hline Total bilirubin, $\mu \mathrm{mol} / \mathrm{L}$ & $12.4 \pm 7.4$ & $13.6 \pm 7.1$ & $11.9 \pm 7.5$ & 0.073 \\
\hline Albumin, g/L & $37.1 \pm 6.3$ & $37.4 \pm 5.8$ & $37.0 \pm 6.5$ & 0.573 \\
\hline Haemoglobin, g/L & $124.9 \pm 17.1$ & $127.8 \pm 16.8$ & $123.7 \pm 17.1$ & 0.064 \\
\hline Leptin, ng/ml & $18.5 \pm 23.2$ & $11.7 \pm 18.6$ & $21.1 \pm 24.3$ & 0.002 \\
\hline Adiponectin, ng/ml & $17.5 \pm 7.4$ & $15.6 \pm 7.6$ & $18.3 \pm 7.1$ & 0.007 \\
\hline Resistin, ng/ml & $18.7 \pm 10.5$ & $18.7 \pm 10.7$ & $18.6 \pm 10.4$ & 0.978 \\
\hline Leptin/adiponectin ratio & $1.5 \pm 2.4$ & $1.1 \pm 1.6$ & $1.6 \pm 2.7$ & 0.121 \\
\hline Leptin/resistin ratio & $1.4 \pm 2.1$ & $0.8 \pm 1.0$ & $1.6 \pm 2.3$ & 0.006 \\
\hline Adiponectin/resistin ratio & $1.3 \pm 1.5$ & $1.1 \pm 0.9$ & $1.4 \pm 1.7$ & 0.148 \\
\hline $25(\mathrm{OH}) \mathrm{D}, \mathrm{nmol} / \mathrm{L}$ & $37.3 \pm 18.0$ & $42.4 \pm 18.2$ & $35.3 \pm 17.6$ & 0.003 \\
\hline PTH, pmol,L & $6.9 \pm 5.6$ & $5.5 \pm 3.5$ & $7.4 \pm 6.1$ & 0.009 \\
\hline TSH (mU/L) & $1.55 \pm 2.17$ & $1.36 \pm 1.35$ & $1.62 \pm 2.41$ & 0.382 \\
\hline Free T4 (pmol/L & $15.9 \pm 3.54$ & $15.2 \pm 3.53$ & $16.2 \pm 3.50$ & 0.021 \\
\hline $\mathrm{eGRF}, \mathrm{ml} / \mathrm{min} / 1.73 \mathrm{~m} 2$ & $65.1 \pm 23.7$ & $71.2 \pm 26.4$ & $62.7 \pm 22.2$ & 0.006 \\
\hline *HbA1c, \% & $6.6 \pm 1.04$ & $6.7 \pm 1.29$ & $6.6 \pm 0.94$ & 0.825 \\
\hline
\end{tabular}

Data are mean \pm SD. GGT, gamma-glutamyltransferase; ALT, alanine aminotransferase; ALP, alkaline phosphatase; $25(\mathrm{OH}) \mathrm{D}$, 25-hydroxyvitamin D; $\mathrm{PTH}$, parathyroid hormone; TSH, thyroid-stimulating hormone; T4, thyroxin; eGFR, estimated glomerular filtration rate; * $\mathrm{HbA1c}$, glycosylated haemoglobin, measured only in patients with type 2 diabetes mellitus.

\section{Ageing mediated changes in serum metabolic parameters}

The results of Pearson's correlations between liver markers, other parameters and age are shown in Table 2. GGT, ALT, leptin and eGFR were inversely associated with age, whereas adiponectin, resistin, PTH, creatinine, and urea were positively correlated with age. As might be expected, age showed a significant positive association with American Society of Anaesthesiologists (ASA) score $(\mathrm{r}=0.224 ; \mathrm{p}=0.001)$ and presence of dementia $(\mathrm{r}=0.214 ; \mathrm{p}=0.001)$. There was no significant association between any other studied parameters and age.

Study subjects were further classified into three age groups: $<75,75-85$ and $>85$ years (Table 3 ). In the oldest patients (aged $>85$ years), compared to aged $<$ 75 years, the mean GGT activity was $50.6 \%$ and the ALT activity $48.4 \%$ lower; the mean leptin, $25(\mathrm{OH}) \mathrm{D}$ and eGFR levels were also $36.5 \%, 14.6 \%$ and $29.4 \%$ lower, respectively, while adiponectin $(+42.2 \%)$, resistin $(+25.1 \%)$ and PTH $(+72.3 \%)$ demonstrated an opposite trend (all $\mathrm{p}$ for trend $<0.05$ ). No associations between age and ALP, albumin, bilirubin, TSH, T4, $\mathrm{HbA1c}$ were found.

Table 2. Association between age and parameters of liver, renal, thyroid functions, adipokines and haemoglobin in older patients with hip fractures (Pearson correlation coefficients)

\begin{tabular}{lll}
\hline Variable & $\mathrm{r}$ & P Value \\
\hline GGT & -0.198 & 0.001 \\
ALT & -0.134 & 0.022 \\
ALP & -0.076 & 0.192 \\
Bilirubin & 0.006 & 0.920 \\
Albumin & -0.060 & 0.308 \\
Leptin & -0.159 & 0.007 \\
Adiponectin & 0.248 & $<0.001$ \\
Resistin & 0.148 & 0.018 \\
Egfr & -0.313 & $<0.001$ \\
Creatinine & 0.202 & 0.005 \\
Urea & 0.296 & 0.001 \\
25 (OH)D & -0.003 & 0.958 \\
PTH & 0.250 & $<0.001$ \\
TSH & 0.032 & 0.594 \\
T4 & -0.027 & 0.662 \\
Haemoglobin & -0.110 & 0.058 \\
ASA score & 0.224 & 0.001 \\
Dementia & 0.212 & 0.001 \\
\hline
\end{tabular}

Data were log transferred before analysis (to achieve normal distribution). GGT, gamma-glutamyltransferase; ALT, alanine aminotransferase; ALP, alkaline phosphatase; 25(OH)D, 25-hydroxyvitamin D; PTH, parathyroid hormone; TSH, thyroid-stimulating hormone; T4, thyroxin; eGFR, estimated glomerular filtration rate; ASA, American Society of Anaesthesiologists.

Table 3. Liver and renal parameters, adipokines, vitamin D, PTH and haemoglobin levels in older patients with hip fracture by age

\begin{tabular}{lllll}
\hline \multirow{2}{*}{ Variable } & Age (years) & & \\
\cline { 2 - 4 } & $<75(\mathrm{n}=52)$ & $\begin{array}{l}75-85 \\
(\mathrm{n}=145)\end{array}$ & $>85(\mathrm{n}=97)$ & P Value \\
\hline Age, mean \pm SD & $69.3 \pm 5.0$ & $81.2 \pm 2.7$ & $90.1 \pm 3.5$ & $<0.001$ \\
GGT, U/L & $85.6 \pm 65.1$ & $50.7 \pm 77.2$ & $42.3 \pm 61.5$ & 0.010 \\
ALT, U/L & $37.8 \pm 29.0$ & $21.1 \pm 24.1$ & $19.5 \pm 18.5$ & 0.010 \\
ALP, U/L & $114.6 \pm 89.5$ & $104.1 \pm 76.1$ & $102.5 \pm 66.4$ & 0.564 \\
Bilirubin, $\mu \mathrm{mol} / \mathrm{L}$ & $12.3 \pm 8.3$ & $12.5 \pm 7.7$ & $12.2 \pm 6.4$ & 0.948 \\
Albumin, g/L & $38.1 \pm 5.4$ & $36.8 \pm 6.1$ & $36.9 \pm 6.1$ & 0.438 \\
*HbA1c, \% & $6.6 \pm 1.0$ & $6.6 \pm 1.0$ & $6.5 \pm 1.2$ & 0.971 \\
Leptin ng/ml & $20.8 \pm 24.7$ & $21.2 \pm 26.5$ & $13.2 \pm 14.9$ & 0.026 \\
Adiponectin, ng/ml $\mathrm{13.5} \pm 6.5$ & $17.8 \pm 7.9$ & $19.2 \pm 6.2$ & 0.001 \\
Resistin, ng/ml & $16.7 \pm 10.3$ & $17.9 \pm 9.6$ & $20.9 \pm 11.4$ & 0.044 \\
25 (OH) D, nmol/L & $39.7 \pm 15.9$ & $37.1 \pm 19.0$ & $33.9 \pm 17.5$ & 0.035 \\
PTH, pmol/L & $4.7 \pm 3.1$ & $6.8 \pm 5.0$ & $8.1 \pm 7.0$ & 0.002 \\
eGFR, & $82.9 \pm 25.2$ & $63.1 \pm 21.5$ & $58.5 \pm 21.5$ & $<0.001$ \\
ml/min/1.73m ${ }^{2}$ & & & & \\
Hb, g/L & $129.8 \pm 17.4$ & $124.4 \pm 18.0$ & $122.9 \pm 15.1$ & 0.051 \\
\hline
\end{tabular}

Data are the mean \pm SD. P value for trend. GGT, gamma-glutamyltransferease; ALT alanine aminotranferase; ALP, alkaline phosphatase; *HbA1c, glycosylated haemoglobin, measured only in patients with type 2 diabetes mellitus; $25(\mathrm{OH}) \mathrm{D}$, 25hydroxyvitamin D; PTH, parathyroid hormone; eGFR, estimated glomerular filtration rate; $\mathrm{Hb}$, haemoglobin. 


\section{Links between liver markers and comorbidities}

Parameters of liver function were compared between patients with and without specific co-morbid conditions. Lower ALT levels $(\leq 20 \mathrm{IU} / \mathrm{L})$ were associated with dementia $(\mathrm{OR}=2.11,95 \% \mathrm{CI} 1.10-4.05, \mathrm{p}=$ 0.015). Lower GGT levels ( $\leq 30 \mathrm{U} / \mathrm{L})$ were prevalent in females $(\mathrm{OR}=1.88,95 \% \mathrm{CI} 1.09-3.25, \mathrm{p}=0.016)$. Higher GGT levels (>30IU/L) were associated with coronary artery disease $(\mathrm{CAD}, \mathrm{OR}=2.55,95 \% \mathrm{CI} 1.37-4.74$, $\mathrm{p}=0.003)$, type $2 \mathrm{DM}(\mathrm{OR}=2.19,95 \% \mathrm{CI} 1.12-4.29$, $\mathrm{p}=0.013)$, and excess alcohol consumption ( $>3$ times a week, OR=6.39, 95\%CI $1.6-29.57, \mathrm{p}=0.002)$, while total bilirubin levels above $20 \mu \mathrm{mol} / \mathrm{L}$ were associated with $\mathrm{CAD}(\mathrm{OR}=2.56,95 \% 1.01-6.42, \mathrm{p}=0.025)$, cervical (vs. trochanteric) HF type (OR=3.26, 95\%CI 1.27 8.72, $\mathrm{P}=0.006)$ and alcohol overuse $(\mathrm{OR}=4.67,95 \% \mathrm{CI}$ 1.12 - 18.19, $\mathrm{p}=0.008)$. Albumin concentrations above $33 \mathrm{~g} / \mathrm{L}$ were associated with $\mathrm{CAD}(\mathrm{OR}=3.13,05 \% \mathrm{CI}$ $1.21-8.5, \mathrm{p}=0.009)$. On the other hand, the majority of 51 patients without prevalent $\mathrm{CVD}, \mathrm{CKD} \geq 3$ stage, $\mathrm{DM}$, and non-alcohol overusers, had ALT $\leq 20 \mathrm{U} / \mathrm{L}$ $(70.6 \%), \quad$ GGT $\leq 30 \mathrm{U} / \mathrm{L} \quad(66.7 \%), \quad$ albumin $>33 \mathrm{~g} / \mathrm{L}$ $(74.5 \%)$ and bilirubin<20 $2 \mathrm{~mol} / \mathrm{L}(94.1 \%)$.

\section{Correlations between liver markers and other parameters}

Pearson's correlation coefficient between log ALT and log GGT was 0.372 ( $p<0.001)$. Both GGT and ALT were also significantly and positively associated with ALP $(\mathrm{r}=0.426 ; \mathrm{p}<0.001$ and $\mathrm{r}=0.141 ; \mathrm{p}=0.015$, respectively), and bilirubin $(\mathrm{r}=0.218 ; \mathrm{p}=0.001$, and $\mathrm{r}=0.171 ; \mathrm{p}=0.003$, respectively). ALT inversely correlated with albumin $(\mathrm{r}=-0.124 ; \mathrm{p}=0.034)$. ALP was negatively associated with $25(\mathrm{OH}) \mathrm{D}(\mathrm{r}=-0.187$, $\mathrm{p}=0.002)$. Bilirubin correlated with resistin $(\mathrm{r}=0.151$, $\mathrm{p}=0.016)$, and PTH with adiponectin ( $\mathrm{r}=0.193$, $\mathrm{p}=0.002)$. No other associations were found between GGT, ALT, bilirubin, albumin, on one hand, and $25(\mathrm{OH}) \mathrm{D}, \mathrm{PTH}$ and adipokines, on the other hand. However, GGT correlated positively with TSH $(\mathrm{r}=0.116 . \mathrm{p}=0.05)$ and negatively with $\mathrm{T} 4(\mathrm{r}=-0.185, \mathrm{p}=$ $0.002)$. There was also a significant inverse association between leptin and adiponectin $(r=-0.178, p=0.005)$.

Multiple linear regression analysis with GGT as the dependent variable and age, sex, ALT, ALP, bilirubin, albumin, eGFR, three adipokines (adiponectin, leptin and resistin), 25(OH)D, PTH, T4 levels, alcohol consumption (>3 times/week, yes/no), presence of DM (yes/no), and CVD (yes/no) as independent variables revealed eight independent and significant determinants of GGT (as a continuous variable): ALT, ALP, bilirubin, adiponectin, alcohol overuse, DM (all six positively related), albumin and age (both inversely related). This model explained $54.3 \%$ of the variance in serum GGT activity (Table 4). Similar analyses for four other liver markers, namely ALT, ALP, bilirubin and albumin, as dependent parameters in separate regression models showed that GGT was an independent and significant predictor for each of these liver function parameters $(\beta=0.112, p=0.10$; $\beta=0.541, p<0.001 ; \beta=0.019, p=0.004 ; \beta=-0.012, p=0.039$, respectively). When multiple linear regression analysis was performed with adiponectin as the dependent variable three independent significant associations were found: age $(\beta=0.232, p=0.001)$, male sex $(\beta=$ -2.500, $\mathrm{p}=0.031)$ and PTH $(\beta=0.185, \mathrm{p}=0.0 .40)$.

Table 4. Multivariate linear regression analyses for serum gamma-glutamyltransferase (GGT) level as a dependant continuous (model 1 ) and categorical (>30 U/L, model 2) variable

\begin{tabular}{llllll}
\hline \multicolumn{5}{c}{ Model 1 } & \multicolumn{5}{l}{ Model 2 } \\
\hline & $\beta$ & P Value & OR & $95 \%$ CI & P Value \\
\hline Age & -2.464 & $<0.001$ & 0.98 & $0.94-1.03$ & 0.563 \\
Sex (m) & 2.008 & 0.852 & 2.53 & $1.28-5.03$ & 0.008 \\
ALT & 0.263 & 0.010 & 1.04 & $1.01-1.06$ & 0.013 \\
ALP & 0.637 & $<0.001$ & 1.01 & $1.01-1.02$ & 0.015 \\
Bilirubin & 1.869 & 0.004 & 1.01 & $0.94-1.06$ & 0.602 \\
Albumin & -1.554 & 0.039 & 1.01 & $0.95-1.06$ & 0.738 \\
Adiponectin & 1.403 & 0.034 & 1.06 & $1.02-1.11$ & 0.009 \\
*Alcohol & 92.368 & $<0.001$ & 6.13 & $1.44-26.02$ & 0.015 \\
DM & 30.560 & 0.048 & 2.29 & $1.03-5.07$ & 0.041 \\
& $\mathrm{R}^{2}=0.5426$ & & $\mathrm{R}^{2}=0.1924$ & &
\end{tabular}

$\beta$, parameter estimate/regression coefficient; OR, odds ratio; CI, confidence interval; ALT alanine aminotranferase; ALP, alkaline phosphatase; DM, diabetes mellitus. *Alcohol consumption $\geq 3$ times a week.

Adjustments: age, sex, ALT, ALP, bilirubin, albumin, adiponectin, leptin, resistin, $25(\mathrm{OH}) \mathrm{D}, \mathrm{PTH}$, estimated glomerular filtration rate (eGFR), alcohol overuse, presence of type 2 diabetes mellitus and cardiovascular disease. Only statistically significant associations (at least in one model) shown $(\mathrm{p}<0.05)$.

In multivariate adjusted regression model that included GGT $>30 \mathrm{U} / \mathrm{L}$ as the dependent variable and the same independent variables, the significant associations showed adiponectin, male sex, ALT, ALP, alcohol overuse and DM (Table 4, model 2). In multivariate regression analyses, ALT $<20 \mathrm{U} / \mathrm{L}$ was independently predicted only by GGT (OR=0.992, $\mathrm{p}=0.021)$, and albumin $<33 \mathrm{~g} / \mathrm{L}$ was predicted only by GGT (OR=0.995, $\mathrm{p}=0.033$ ) and ALP (OR=1.006, $\mathrm{p}=$ 0.040). Compared to the rest of the cohort, the patients with GGT>30U/L $(105.7 \pm 65.5$ vs. $19.6 \pm 5.1 \mathrm{U} / \mathrm{L})$ had also significantly higher levels of ALT (31.9 \pm 35.8 vs. $17.2 \pm 8.2 \mathrm{U} / \mathrm{L}, \mathrm{p}=0.004), \operatorname{ALP}(129.4 \pm 109.4$ vs. $89.3 \pm$ $45.8 \mathrm{U} / \mathrm{L}, \mathrm{p}<0.001)$, bilirubin $(13.7 \pm 9.0$ vs.11.5 \pm 6.0 $\mu \mathrm{mol} / \mathrm{L}, \mathrm{p}=0.011)$, adiponectin (18.8 \pm 7.4 vs. $16.6 \pm 7.2$ $\mathrm{ng} / \mathrm{ml}, \mathrm{p}=0.015)$ and resistin $(20.3 \pm 10.9$ vs. $17.5 \pm$ $10.0 \mathrm{ng} / \mathrm{ml}, \mathrm{p}=0.038$ ).

On subgroup analysis of patients with vitamin $\mathrm{D}$ insufficiency $(25(\mathrm{OH}) \mathrm{D}<50 \mathrm{nmol} / \mathrm{L}, \mathrm{n}=222)$, the subjects with elevated PTH levels ( $>6.8 \mathrm{pmol} / \mathrm{L}, \mathrm{n}=98)$ compared to those with PTH within the reference 
range $(n=124)$ demonstrated a significantly higher mean adiponectin concentration (19.8 \pm 7.3 vs. $16.0 \pm 7.1$ $\mathrm{ng} / \mathrm{ml}, \mathrm{p}=0.001)$, while $25(\mathrm{OH}) \mathrm{D}$ levels were similar $(29.0 \pm 11.96$ vs. $31.3 \pm 11.83 \mathrm{nmol} / \mathrm{L}, \mathrm{p}=0.194)$. It appears, therefore, that elevated PTH (not vitamin D insufficiency per se) modulates adiponectin production by adipose tissue.

Taken together, these data show strong bidirectional associations between GGT and ALT, ALP, bilirubin (all positive) and albumin (negative), and confirm that both DM and alcohol overuse are independent predictors of higher GGT. More importantly, the results indicate that in older patients with HF circulating adiponectin, which rises with ageing in parallel with PTH, is an independent and significant determinant of serum GGT activity. Multiple regression analysis adjusted for possible covariates, including alcohol consumption and DM, identified that for every $1 \mathrm{ng} / \mathrm{ml}$ increment of serum adiponectin concentration the probability of higher GGT(>30 U/L) increase by $6.2 \%$. With age both GGT and ALT decrease, while PTH and adiponectin levels increase, and the latter seems to have a greater effect on serum GGT activity than age. These complex relationships are depicted in Figure 1.

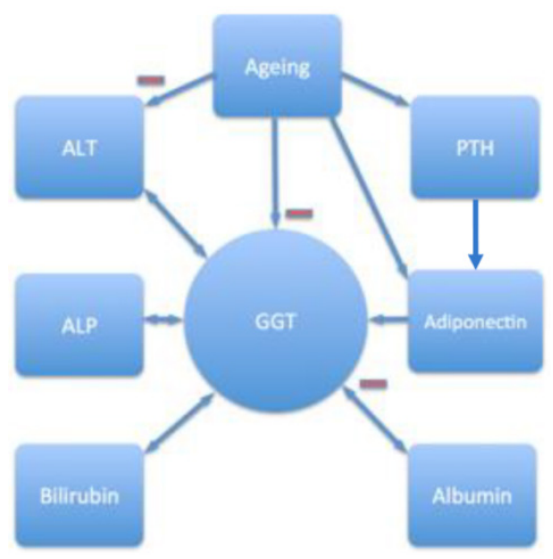

Figure 1. Relationships between age, liver function parameters, circulating levels of adiponectin and PTH (independent and significant associations shown). GGT, gamma-glutamyltransferase; ALT alanine aminotranferase; ALP, alkaline phosphatase; PTH, parathyroid hormone; $\square$ negative correlation. Ageing is associated with decreased GGT and ALT activities and higher serum PTH and adiponectin levels. PTH correlates with adiponectin and adiponectin is associated with higher GGT levels. A bidirectional relationship links GGT with ALT, ALP and bilirubin (positively) and albumin (negatively).

\section{Liver markers and short-term outcomes}

In our cohort, the prevalence of prolonged LOS (>20days) was 31.6\% (n=94), and the in-hospital death rate was $4.8 \%(\mathrm{n}=14)$. Myocardial injury (cTnI rise) was observed in $27.2 \%(\mathrm{n}=80)$ of patients, a high post-operative inflammatory response (CRP>100 $\mathrm{mg} / \mathrm{L})$ in $60.2 \%(\mathrm{n}=177)$ and $49 \%$ of patients admitted from home have been discharged to a permanent residential care facility.

When serum parameters (log transformed) of liver function were analysed as continuous variables by Pearson correlation, GGT activity correlated positively with prolonged hospital stay $(\mathrm{r}=0.140, \mathrm{p}=0.020)$, and ALP correlated with a higher post-operative inflammatory response $(\mathrm{r}=0.123, \mathrm{p}=0.036)$; albumin correlated inversely with in-hospital death $(\mathrm{r}=-0.137$, $\mathrm{p}=0.005)$, postoperative cTnI rise $(\mathrm{r}=-0.292, \mathrm{p}<0.001)$ and need to be discharged to a permanent residential care facility $(r=-0.151 . p=0.002)$.

When each liver marker was examined as a categorical variable in multivariate adjusted analysis (with age, sex, other liver parameters and eGFR as independent variables), GGT $>30 \mathrm{U} / \mathrm{L}$ was associated with 1.9-fold increases in prolonged hospital stay and albumin $<33 \mathrm{~g} / \mathrm{L}$ was associated with a 3 -fold higher in-hospital mortality (Table 5). These findings remained consistent or even stronger after further adjustment for serum leptin, adiponectin, resistin levels, ratios leptin/adiponectin, leptin/resistin and adiponectin/resistin, 25(OH)D and PTH (model 2), as well as such potential confounders as alcohol consumption, smoking (current or previous), presence of DM and CVD (Table 5, model 3). Of note, in multivariate analyses, adiponectin $(\mathrm{p}=0.031), \mathrm{PTH}$ $(p=0.001)$, age $(p=0.051)$ and smoking history $(p=0.007)$ were also independent predictors of prolonged hospital stay, while PTH $(\mathrm{p}=0.001)$ and male sex $(p=0.03)$ were independently associated with in-hospital death. In patients with LOS $>20$ days, compared to the rest of the cohort, the mean adiponectin levels were significantly higher (18.9 \pm 7.9 vs.16.4 $\pm 7.0 \mathrm{ng} / \mathrm{ml}, \mathrm{p}=0.022)$. Serum adiponectin concentration above the median level $(17.14 \mathrm{ng} / \mathrm{ml})$ 2-fold increases the risk of prolonged hospital stay (OR 2.01, 95\% CI 1.16-3.77, $\mathrm{p}=0.014$ ) after adjustments for age, sex, liver markers, 25(OH)D, PTH, eGFR, presence of CVD and DM.

Table 5. Liver function parameters at admission as independent predictors of poorer outcomes in older patients with hip fracture

\begin{tabular}{lllll}
\hline Parameter & Outcome & Model & OR $(95 \% \mathrm{CI})$ & P Value \\
\hline GGT $>30 \mathrm{U} / \mathrm{L}$ & LOS>20 days & 1 & $1.86(1.09-3.19)$ & 0.023 \\
& & 2 & $1.98(1.12-3.49)$ & 0.019 \\
& 3 & $1.74(1.08-3.10)$ & 0.038 \\
Albumin<33g/1 In-hospital death & 1 & $3.13(1.01-9.09)$ & 0.049 \\
& 2 & $3.45(1.08-11.11)$ & 0.038 \\
& 3 & $11.11(2.33-50.00)$ & 0.003
\end{tabular}

GGT, gamma-glutamyltransferase; LOS, length of hospital stay; OR, odds ratio; CI, confidence interval.

Model 1: adjusted for age, sex, liver function parameters (GGT, ALT, ALP, bilirubin, albumin, except the evaluated categorical variable), and estimated glomerular filtration rate $(\mathrm{n}=293)$.

Model 2: Model 1 plus serum leptin, adiponectin, resistin, ratios lep-

tin/adiponectin, leptin/resistin, adiponectin/resistin, 25(OH)D and PTH $(n=285)$.

Model 3: Model 2 plus alcohol consumption ( $\geq 3$ times a week), smoking (current or previous), presence of type 2 diabetes mellitus, cardiovascular disease (hypertension, coronary artery disease, history of stroke, atrial fibrillation) $(\mathrm{n}=285)$. 
The prognostic value of GGT $>30 \mathrm{U} / \mathrm{L}$ for prolonged LOS [accuracy $60.4 \%$, 95\% CI 54.7 - 66.1\%, sensitivity $48.9 \%$, 95\%CI 39.9 - 57.8\%; specificity 65.8\%, 95\%CI 61.6 - 69.9\%; PPV 39.8\%, 95\% CI 32.5 47.1\%; NPV 73.5\%, 95\%CI 68.9 - 78.1\%] was comparable with that of higher adiponectin level (cut-off $17.14 \mathrm{ng} / \mathrm{ml}$ ) [accuracy 57.9\%, 95\% CI 51.6 - 63.7\%, sensitivity $61.5 \%$, 95\%CI 51.8 - 70.7\%; specificity 56.1\%, 95\% CI 51.5 - 60.4\%; PPV 40.0\%, 95\%CI 33.6 45.9\%; NPV 75.4\%, 95\%CI 69.2 - 81.3\%]. However, higher GGT and adiponectin levels show synergistic prognostic value for prolonged hospital stay: the risk increases 4.7-times in patients with both these characteristics compared to subjects with none of such features (Figure 2). These two biomarkers, although interrelated, are associated with different specific pathogenetic processes; thus, for predicting LOS a two-marker approach (two biomarkers measured in parallel) is described. Compared with presence only of one of these biomarkers, combined GGT $>30 \mathrm{U} / \mathrm{L}$ plus adiponectin $>17.14 \mathrm{ng} / \mathrm{ml}$, as would be expected, demonstrated an improvement of prognostic accuracy (72.3\%, 95\%CI $66.9-77.3)$, specificity $(83.2 \%$, 95\% CI $79.2-86.8 \%)$ and PPV $(57.3 \%, 95 \%$ CI $47.4-66.6 \%)$, while the sensitivity $(48.9 \%, 95 \% \mathrm{CI} 40.4-56.8 \%)$, and NPV $(77.8 \%$, 95\% CI $74.2-81.3 \%)$ unchanged.

Serum albumin $<33 \mathrm{~g} / \mathrm{L}$ has the following prognostic value for in-hospital deaths: accuracy $77.2 \%$, $95 \%$ CI 75.0 - 79.8, sensitivity $42.9 \%$, 95\%CI $19.1-$ 69.7\%; specificity 78.9\%, 95\%CI 77.7 - 80.3\%; PPV 9.2\%, 95\%CI 4.1 - 15.0\%; NPV 96.5\%, 95\%CI 95.1 $98.1 \%$.

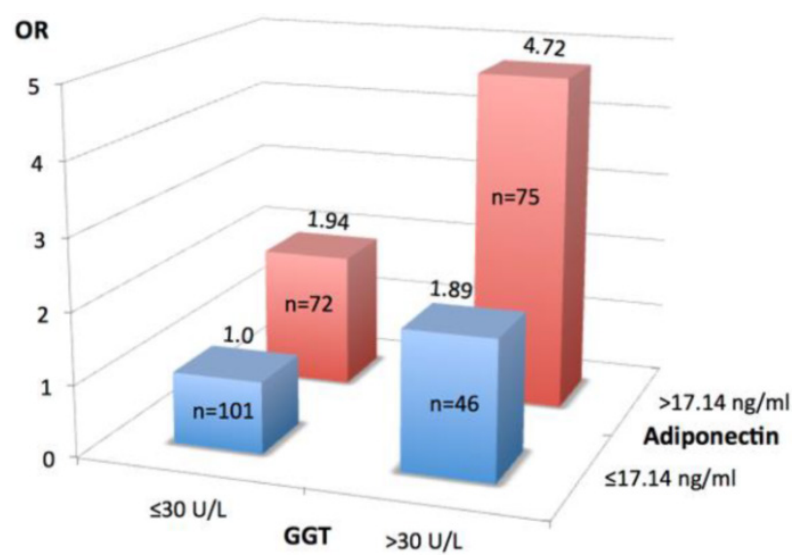

Figure 2. Association between prolonged hospital stay ( $>20$ days) and gamma-glutamyltransferase (GGT) and adiponectin profiles. Study patients were classified into four groups according to serum levels of GGT $(\leq 30 \mathrm{U} / \mathrm{L}$ or $>30 \mathrm{U} / \mathrm{L}$ ) and adiponectin $(\leq 17.14 \mathrm{ng} / \mathrm{ml}$ and $>17.14 \mathrm{ng} / \mathrm{ml})$. Values are odds ratio (OR) adjusted for age, sex, alcohol consumption, presence of type 2 diabetes and cardiovascular disease. Number of subjects in each group is shown in the column. Group $1(n=101)$-reference $(O R=1.0)$, group $2(n=46)$-high $G G T$ and low adiponectin $(\mathrm{OR}=1.89,95 \% \mathrm{Cl} 1.29-4.49, \mathrm{p}=0.026)$, group $3(\mathrm{n}=72)$ - low GGT and high adiponectin $(O R=1.94,95 \% \mathrm{Cl} 1.64-3.22, p=0.004)$, group $4(n=75)$ - high GGT and high adiponectin $(\mathrm{OR}=4.72,95 \% \mathrm{Cl} 2.58-8.65, \mathrm{p}=0.001)$. Of note, both higher serum GGT (>30U/L) and adiponectin (>17.14 ng/L) levels are synergistically associated with prolonged LOS.

\section{Discussion}

\section{Main findings}

The results of this observational study of older HF patients showed that: (1) the prevalence of abnormal liver function tests is relatively low, but hepatic functions (even within normal range) are associated with common age-related disorders, (2) with age GGT and ALT activities decrease, while serum PTH and adiponectin concentrations increase, (3) adiponectin is an independent contributor to higher GGT, which, in turn, demonstrates bidirectional links with ALT, ALP, bilirubin and albumin levels, and (4) GGT $>30 \mathrm{U} / \mathrm{L}$ and albumin $<33 \mathrm{~g} / \mathrm{L}$ on admission, regardless of other traditional risk factors, are useful independent predictors of prolonged LOS and in-hospital mortality, respectively.

Our work corroborates previous studies showing age-related decline in hepatic function, extends the understanding of the liver status and the role of adipokines, especially adiponectin, in its regulation in the elderly patients with $\mathrm{HF}$, and presents novel findings of pathophysiological and clinical importance.

\section{Liver markers and related parameters in patients with hip fracture according to age}

We found that in older HF patients the prevalence of abnormally elevated ALT, GGT, ALP or bilirubin on admission was relatively low $(<10 \%$, ranging between $1.7 \%$ and $9.9 \%$ ) and comparable with or even lower than that reported in population-based studies, ${ }^{17,71-75}$ as well as in a cohort of orthopaedic patients. 59

In our study, ageing was closely linked with decline in GGT, ALT and leptin concentrations and increasing adiponectin and PTH levels, both in correlation analyses and when young old ( $<75$ years) patients where compared to the old-old ( $>85$ years); adiponectin, leptin and PTH concentrations were significantly higher in females than in males. These findings are consistent with many, but not all 21,76,77 previous reports that serum GGT ${ }^{5,9}$ and ALT $^{6,8-10,73,}$ 78-81 activities (within reference range as well as elevated) are negatively associated with age. We observe neither a decline in serum albumin, nor an increase in bilirubin with increasing age as it was reported by some authors. ${ }^{9}$ No gender dependence in the mean values of liver markers was found, although lower GGT levels ( $\leq 30 \mathrm{U} / \mathrm{L})$ were about 2-times prevalent in females; this is in agreement with previous studies that men had significantly higher concentrations of GGT than women.5, 21, 23 Our data are in agreement with earlier studies showing age-related increase of circulating adiponectin ${ }^{82-86}$ and decrease of leptin 
levels, $, 87,88$ and with the well-recognized fact that both these adipokines are higher in women than in men. In previous reports, as in ours, PTH levels were significantly associated with age and higher in women than in men. ${ }^{89-94}$ However, such influence of age and gender on PTH was not observed in a recent study of 35-65 year old healthy adults. ${ }^{95}$ These discrepancies might be due, at least partially, to the higher mean age in our cohort.

\section{Liver markers and comorbidities}

The high burden of pre-existing comorbidities at time of HF and its important affect on outcomes are well known, but the role and impact of liver function status on comorbidities has not yet been examined in the setting of HF. In our study, higher GGT levels (>30U/L), as might be expected, were associated with CAD, DM, and excess alcohol consumption, while lower ALT levels $(\leq 20 \mathrm{U} / \mathrm{L})$ were associated with dementia; total bilirubin levels above $20 \mu \mathrm{mol} / \mathrm{L}$ were associated with CAD, cervical (vs. trochanteric) HF type and alcohol overuse, and albumin concentrations above $33 \mathrm{~g} / \mathrm{L}$ were associated with CAD. These findings may indicate that even in the absence of overt liver disease hepatic functions are implicated in the pathogenesis of age-related disorders rather than merely be bystanders of ageing.

Our findings are consistent with numerous studies and meta-analysis showing the association between serum GGT levels (within normal limits) and CAD, 21-23, 46, 47, 77, 96-102 DM, 25, 47, 103, 104 alcohol consumption, ${ }^{32,} 47,105$ cardiovascular and all-cause mortality in older adults, 14, 18, 24, 105, 106 and the contribution of GGT to the pathogenesis of atherosclerotic plaques. ${ }^{46,107,108}$ Our data are also consistent with reports that ALT is poorly linked to CVD, 35,36 and GGT (but not ALT), which is regarded as less specific for liver injury than ALT, is significantly associated with insulin resistance in non-diabetic subjects. ${ }^{109}$ Of note, results of our multivariate analysis demonstrated that DM and alcohol overuse were significant determinants of higher GGT (both as a continuous or categorical variable), but presence of CVD was not an independent predictor of GGT, suggesting that shared factors influence the pathogenetic relationship between the liver and CVD. The association of lower ALT levels with dementia is plausible given that ageing is a multidimensional process and age-related decrease in ALT, a highly specific liver enzyme restricted to the cytosolic component of hepatocytes, ${ }^{110}$ may signify a decrease in the mass and function of the normal liver ${ }^{6,7}$ in parallel with progressive decline of other vital functions.

In our cohort, contrary to some previous studies, higher bilirubin levels were associated with CAD. Low bilirubin levels have been reported to be associ- ated with $C A D, 111$ its severity, ${ }^{112}$ increased carotid intima-media thickness, ${ }^{113}$ carotid atherosclerosis, ${ }^{114}$ peripheral arterial disease, ${ }^{115}$ and total mortality, ${ }^{116}$ while higher levels or mild to moderate elevations were associated with a protective effect against coronary microvascular dysfunction, 117 reduced cardiovascular events ${ }^{118}$ and stroke, ${ }^{119-121}$ as well as CAD in subjects with Gilbert syndrome. ${ }^{122}$ On the other hand, total bilirubin has been shown to be a strong and independent predictor of morbidity and mortality in patients with heart failure, ${ }^{123-126}$ acute myocardial infarction, 127,128 and after heart valve surgery. ${ }^{129}$

Reports on the relationship between serum albumin level and atherosclerotic CVD are also conflicting, demonstrating a negative, ${ }^{111,130}$ positive, ${ }^{131-133}$ or no association. ${ }^{134,135}$ A recent study showed that higher albumin levels were associated with insulin resistance, but did not predict the development of diabetes. ${ }^{136}$ In our cohort, the odds ratio for presence of CAD was 3.1 in patients with serum albumin above 33g/L. A possible explanation for the associations between higher bilirubin levels and/or normal albuminaemia with CVD is that individuals with lower bilirubin or albumin levels have already died by the time of HF. In the current as many previous studies $^{61-68,137}$ hypoalbuminaemia was strongly associated with mortality. Therefore, the high-normal bilirubin and/or albumin levels in our older HF patients with CAD are not contradictory to observations of negative correlations between serum albumin and/or bilirubin levels and cardiovascular risk factors, as well as CAD.

The abovementioned conflicting findings regarding the associations between liver markers and comorbidities might be attributable to different characteristics of the study populations (age and sex distribution, alcohol consumption and smoking habits, obesity and insulin resistance, presence of metabolic syndrome or DM) and emphasise the complexity of the underlying mechanisms indicating the importance of an integrated approach to interpretation.

\section{Correlations: hepatic markers and adipokines, PTH and vitamin D}

To make matters even more difficult to the interpretation of results, the literature data on the inter-correlations between liver function markers, as well as on correlations between these markers and adipokines, and between adipokines and $25(\mathrm{OH}) \mathrm{D}$ and PTH in different pathologies are controversial.

In our study, GGT activity and other hepatic markers exhibited a bidirectional relationship: a positive with ALT, ALP and bilirubin and a negative with albumin. These observations are in line with many, but not all,120 reports showing significant positive 
correlations between GGT and ALT, 5, 8, 138, 139 ALP140 and bilirubin. ${ }^{141}$ These bidirectional links indicate that GGT activity represents an integral component of liver function.

The adipocytokines adiponectin, leptin and resistin, three best-studied pleiotropic hormones involved in a number of physiological and pathophysiological processes from energy homeostasis to inflammation and immunity, have been implicated in hepatic dysfunction. ${ }^{70,}{ }^{142-150}$ However, in our cohort we were not able to demonstrate an association between leptin or resistin and liver markers, except higher mean resistin levels in patients with GGT>30 $\mathrm{U} / \mathrm{L}$.

In contrast, a main novelty of this study is a significant positive correlation between serum adiponectin, the most abundant adipocytokine, and GGT activity. Yet it should be noted that the robustness of adiponectin as an independent determinant of higher GGT become obvious after adjusting for important confounders (Table 5). Our results are in contrast with those observed in patients with type $2 \mathrm{DM}, 151,152$ visceral obesity, 153 non-alcoholic hepatic steatosis (NASH), ${ }^{154,155}$ as well as in healthy (often overweight and obese) individuals,96, 156-159 and Japanese male workers, 160 in all of which adiponectin levels were negatively correlated with GGT. Although a significant association between ALT and adiponectin was observed in young healthy men, ${ }^{161}$ in the majority of previous studies, as in ours, ALT and ALP levels were not associated with adiponectin. ${ }^{153}, 155,159,162$ Why adiponectin is more strongly linked to GGT than to ALT and other liver markers is not entirely clear. Although serum GGT is predominantly secreted by the liver, it is present and active on the surface of most cell types where it plays an important role in glutathione metabolism; GGT may also capture extra-hepatic processes relevant to ageing.

More importantly, while in DM, metabolic syndrome and NASH adiponectin levels are reduced and aminotransferase activities increased, in advanced liver disease, paradoxically, adiponectin levels are elevated and positively correlate with markers of liver cell injury, including GGT. ${ }^{163-165}$ The contrasting findings in the relationship between adiponectin and liver markers in these diseases may reflect different underlying mechanisms. For example, the strong association between adiponectin and insulin resistance in the first group of conditions ${ }^{166,167}$ was not observed in cirrhotic patients; ${ }^{164}$ in subjects with normal adiponectin and leptin levels liver enzyme activities did not reflect insulin resistance. ${ }^{168}$ It has been suggested that the inverse association between adiponectin and insulin could be a function of suppressed adiponectin secretion by hyperinsulinemia, ${ }^{169}$ although in other studies higher adiponectin levels predicted lower incidence of diabetes independent of prevalent insulin resistance and glycemic status. ${ }^{170,}{ }^{171}$ Possible explanations for these conflicting associations should also include other factors influencing adiponectin levels, such as adipose mass, hepatic ${ }^{163}$ and renal ${ }^{172}$ catabolism, natriuretic peptides, which directly stimulate adiponectin production, ${ }^{22}$ and adiponectin resistance. ${ }^{173}$

The complex pathophysiological role of adiponectin is further reflected in contradictory reports on the relationship between adiponectin levels and mortality in animal and human studies. ${ }^{174-181}$

All these discrepancies should be interpreted in the context of known adiponectin "paradoxes": $182-185$ 1) inverse association of circulating adiponectin level with body weight, obesity/visceral fat percentage; 2 ) metabolically beneficial effects of the hormone (anti-atherogenic, anti-inflammatory, insulin sensitizing, anti-fibrinogenic and anti-apoptotic properties in the liver and other organs) well-documented in experimental and human studies, low serum adiponectin concentrations in non-alcoholic fatty liver disease, atherosclerotic CVD (CAD, stroke, peripheral artery disease), hypertension, DM, metabolic syndrome, and cancers (prostate, colon, gastric, breast, leukemia) in contrast with increased adiponectin levels in advanced liver disease, including NASH-related cirrhosis, as well as in high-risk CVD patients, subjects with chronic heart failure, kidney, pulmonary and connective tissue diseases, preeclampsia, and in critically ill; 3) its favorable (protective) associations with DM, metabolic syndrome and CVD in middle-aged cohorts and the opposite (increased risk of CVD, cardiovascular outcomes and all-cause mortality) for older populations; 4) a U-shaped relationship with CVD, particularly CAD, and mortality in older adults, 186 although the oldest-old individuals ${ }^{83,187,188}$ and centenarians ${ }^{173}$ have higher adiponectin levels than younger subjects. It appears, therefore, that in different pathologies and age groups adiponectin may be regulated in opposite directions.

In the present study, multivariate analysis showed that in older HF patients adiponectin is correlated positively with GGT in contrast to the inverse association reported in other cohorts, including healthy persons and, especially, patients with obesity-associated chronic diseases. The fact that adiponectin was significantly higher in patients with GGT>30U/L, and GGT levels (after controlling for confounding factors) were bidirectionaly inversely correlated with albumin (synthetic liver function), and positively with other hepatic markers (ALT, ALP, bilirubin), but did not predict serum adiponectin concentration, indicates the important regulatory role 
of adiponectin on serum GGT activity.

The age-related increase in adiponectin and its positive association with GGT in our study were independent of other liver parameters (ALT, ALP, bilirubin and albumin), leptin (a sensitive marker of adiposity negatively associated with adiponectin) and resistin (a biomarker strongly associated with an inflammatory response) levels, 25(OH)D, PTH, eGFR, alcohol consumption, presence of $\mathrm{DM}$ or CVD, although some of these factors were also independent contributors to higher GGT levels (Table 4). In other words, the origin of higher serum GGT activity is multifactorial (eight factors accounted for $54.3 \%$ of GGT variance), and the elevated adiponectin concentration and its relation to GGT are part of and reflect the complex homeostatic dysregulation(-s) that accompany ageing. Consistent with this hypothesis, are our findings demonstrating that PTH, which also increases with age, correlated positively with adiponectin and in the multivariate analysis was an independent determinant of adiponectin (but not of leptin or resistin). Of note, despite the marked prevalence of vitamin $\mathrm{D}$ insufficiency in our cohort, with its associated increase in PTH, 25(OH)D levels were not independent contributors of adiponectin, indicating a specific affect of higher PTH levels on production and/or release of adiponectin by adipocytes. Our results are in line with observations that $25(\mathrm{OH}) \mathrm{D}$ is not associated with adiponectin in nondiabetic obese adults, ${ }^{229}$ while PTH is independently associated with adiponectin in patients with heart failure. ${ }^{189}$ However, in patients with primary hyperparathyroidism adiponectin concentrations were found to be normal ${ }^{190}$ or reduced, ${ }^{191,} 192$ did not changed or reversed by parathyroidectomy, ${ }^{190,192}$ and were not associated with PTH levels. ${ }^{193}$ The complex multifactorial origin of GGT activity is further suggested by our observation of its significant correlation with TSH (positive) and T4 (negative); thyroid hormones are known to play an important role in oxidative stress balance. ${ }^{194}$

The positive correlation between PTH and adiponectin has not been previously documented in HF patients, and it may explain, at least partially, the adiponectin-GGT "paradox": although in general with ageing GGT activity decreases, adiponectin levels, mediated in part by elevated PTH, rise resulting in higher GGT levels. We hypothesise that PTH elevation may partly contribute to higher adiponectin concentration, which is clearly related to higher GGT.

\section{Towards an integrated and unifying hypothesis}

Our data in line with numerous previous publications showed that decline in liver functions, increase in adiponectin and PTH are interconnected universal phenomena associated with human ageing.
Age-related rise in serum adiponectin and PTH concentrations are positively correlated, but age and adiponectin are paradoxically compatible with hepatic function, especially with GGT activity. In parallel with adiponectin elevation GGT activity increases indicating that the hormonal effect of adiponectin takes precedence over age-related suppression in the enzyme activity. The serum GGT activity reflects the integrated response of these opposite effects.

These observations raised two key questions: 1) is there a special common cause that underlies the metabolic changes occurring with advancing age, although each change results from an interplay of numerous independent mechanisms, and 2) is higher serum adiponectin concentration associated with GGT elevation, as in our case, an adoptive/compensatory response or a harmful effect.

The exact answers remain largely unknown, and any attempt to adequately explain the observations should include at least two fundamental mechanisms: homeostasis and oxidative stress. Several lines of evidence suggest close but complex interactions between oxidative stress and GGT, albumin, bilirubin, adiponectin and PTH (these factors may act as causes and consequences of oxidative stress). Oxidative stress, an imbalance between the production and inactivation of reactive oxygen species in favour of oxidants accumulation, is widely accepted as an important mechanism associated with human ageing and its adverse effects. ${ }^{195-199}$ Hepatic aging is associated with greater oxidative stress and cell apoptosis. ${ }^{200-202}$ GGT, a membrane-bound enzyme, plays a pivotal role in the intracellular antioxidant defence being involved in the gamma-glutamyl cycle by which extracellular glutathione is transported into cells. Depletion of intracellular glutathione, a principal intracellular antioxidant, ${ }^{203}$ in response to oxidative stress results in an increase in GGT so that the metabolic homeostasis are maintained. Serum GGT activity is inversely associated with the concentration of serum antioxidants. ${ }^{204}$ Serum GGT within its normal range is recognized as a sensitive marker of oxidative stress. ${ }^{30}, 141,203-207$ However, in physiological conditions, GGT may also act as a pro-oxidant, 203, 204, 208 generating reactive oxygen species, 209,210 which could exceed the capacity of the antioxidant system and induce cellular oxidative stress damage.

The oxidative stress responses involve also other potent antioxidants, namely albumin, ${ }^{211}$ the major protein in plasma, which accounts $80 \%$ of thiol's antioxidant effect in the body,212, 213 bilirubin, which protects cells from a 10000 -fold excess of oxidants through rapid regeneration of bilirubin by biliverdin reductase, 119,214 and adiponectin. In animal models ${ }^{215}$, 216 and in humans, 217,218 including the elderly, ${ }^{219}$ adi- 
ponectin inhibits oxidative stress, but oxidative stress suppresses adiponectin production and its powerful protective antioxidant properties. ${ }^{220}$ Importantly, adiponectin is also involved in apoptosis, an evolutionary conserved controlled-death program, which ensures proper regulation of the size and quality of cell populations in tissues.221 PTH may affect oxidative stress directly or by intracellular calcium accumulation. ${ }^{222,}{ }^{223}$ In other words, GGT, albumin, bilirubin, adiponectin and PTH, all of which play a critical role in homeostasis, may be elicited by oxidative stress and/or may have both protective and promoting effects on oxidative stress. The interplay and high degree of complexity of aforementioned and other factors involved in oxidative stress indicate the role of regulatory feedback mechanisms in different conditions. Normally, the oxidative stress responses maintain metabolic homeostasis and are beneficial for adaptation and survival, while dysregulation in the feedback processes may cause the vicious cycle(-s) of oxidants overproduction resulting in aging and aging-related diseases.224 Despite considerable gaps in our knowledge, emerging data suggests that adiponectin and oxidative stress can function in both a defence and harmful manner.

In regard to our observations, age-related decrease of GGT activity may reflect the decline not only in liver function, but in the whole antioxidant defence system (including the decrease in the antioxidant effects of albumin as one of its components), and the increase in serum GGT level may be a compensatory response to oxidative stress, a recognised hallmark of ageing and chronic diseases. This response includes increases in PTH and adiponectin. The former is at least in part responsible for the adiponectin elevation, while the later enhances the anti-oxidant potential in the cells by increasing GGT and promotes apoptosis. ${ }^{225}$ In this way, it can be hypothesized that in our patients, higher GGT activity which is positively associated with both adiponectin and bilirubin (also a potent antioxidant) levels, reflects a compensatory response to oxidative stress. However, in the setting of advanced age and co-morbidities this response is unable fully counter-regulate the oxidative damage and prevent its progression if oxidative stress increases, as in the perioperative period. Indeed, in our cohort, both GGT and adiponectin above the median levels were independently and synergistically associated with prolonged LOS, but not with in-hospital mortality, whereas even mild decrease in albumin concentration, an important extracellular antioxidant, demonstrated a strong relation to fatal outcome. These complex interactions are summarised in Figure 3.

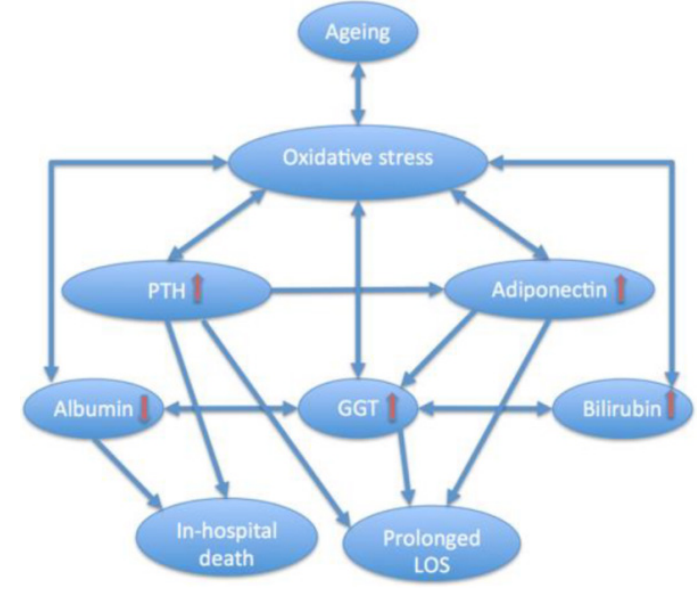

Figure 3. Diagram illustrating complex interplay between ageing, oxidative stress, parathyroid hormone (PTH), adiponectin and gamma-glutamyltransferase (GGT) and other hepatic markers and their relation to short-term outcomes in older patients with hip fracture. LOS, length of hospital stay. In advanced age, GGT, albumin, bilirubin, adiponectin and PTH, all of which are influenced by oxidative stress, may exert both protective and promoting effects on oxidant formation, affect each other, and contribute to poor outcomes. Excessive PTH along with different other age-related factors drives adiponectin levels higher, and such elevations increase GGT activity which reflects an integrative adaptive/compensatory or pathological response (homeostatic regulation or dysregulation). In HF patients, both GGT and adiponectin concentrations above the median levels are independent markers of prolonged LOS and contribute synergistically to this outcome, hypoalbuminaemia is associated with in-hospital death, and hyperparathyroidism is an independent predictor of both fatal outcome and prolonged hospital stay.

\section{Liver markers and short-term outcomes}

Our data shows that in older HF patients liver markers (usually within the normal ranges) on admission are associated with a continuum of risk for poor outcomes. Of clinical interest, GGT, albumin and adiponectin levels analysed as categorical variables (given the practical convenience of cut-off values), independently of known risk factors, may help to identify subjects at increased risk of prolonged hospital stay (LOS>20 days) and in-hospital death. Patients with GGT $>30 \mathrm{U} / \mathrm{L}$ and albumin $<33 \mathrm{~g} / \mathrm{L}$ were near two times as likely to have a LOS $>20$ days, and more than 3 times as likely to have died during hospitalisation, respectively, compared to those without such conditions. The calculated sensitivity and specificity of serum GGT $>30 \mathrm{U} / \mathrm{L}$ for discriminating those with LOS>20 days were $48.9 \%$ and $65.8 \%$, respectively, and of albumin $<33 \mathrm{~g} / \mathrm{L}$ for prediction in-hospital death were $42.9 \%$ and $78.9 \%$, respectively; serum albumin $<33 \mathrm{~g} / \mathrm{L}$ on admission had a NPV of $96.5 \%$. The risk of LOS $>20$ days also doubled in subjects with adiponectin $>17.14 \mathrm{ng} / \mathrm{L}$ (median level). Furthermore, joint effects of GGT $>30 \mathrm{U} / \mathrm{L}$ and adiponectin $>17.14 \mathrm{ng} / \mathrm{ml}$ raised the odds of LOS $>20$ days by 4.7 -fold, demonstrating synergism; the specificity of two markers in combination for predicting LOS $>20$ days was $83.2 \%$. These two biomarkers, although interrelated, are associated with different pathogenetic processes, and, not surprisingly, when 
measured in parallel are more informative for predicting LOS.

Our observations are in line with previous reports that low albumin is of prognostic value on mortality in HF patients. ${ }^{61,62,65,66,69,137,226-228}$ Our data are also concordant with clinical observations that demonstrate that serum GGT, a robust predictor of mortality due to CVD in younger individuals, did not predict mortality in individuals aged 70 years or more. ${ }^{69}$ The prognostic value of GGT and/or adiponectin in HF patients has not been reported previously. Of note, in contrast to the present multivariate analyses, most of the previous prognostic studies in patients with HF examined only few liver parameters (mainly albumin) and often did not control for possible confounders, clinical and laboratory. ${ }^{67}$

The reason(-s) for prolonged LOS among patients with higher GGT and/or higher adiponectin remains unclear. The finding that only GGT and not ALT (a more specific marker of hepatic function), ALP, bilirubin or albumin was associated with LOS in adjusted models may suggest that the GGT -- LOS association reflects not only the liver status but the increased oxidative stress.

The additional (albeit moderate) prognostic information to HF outcomes provided by liver markers, accurate and not expensive laboratory tests, could be helpful in early identification and appropriate treatment of this frail population, and, consequently, improve outcomes, especially prolonged LOS. Currently, HFs represent about two-thirds of all hospital days due to fracture and account for more hospital days than any other musculoskeletal injury. ${ }^{228}$

\section{Limitations and strength of the study}

Several limitations of this study should be considered. First, it was a cross-sectional analysis and, therefore, the cause-effect relationship could not be determined. Second, we measured serum GGT activity and total adiponectin, but the GGT fractions and high-molecular weight adiponectin, shown in some, but not all, ${ }^{185}$ studies to be more informative, were not assessed. Third, potential effects of confounding from variables not represented in our models (e.g. medication used) cannot be excluded. Forth, as the cohort was mainly Caucasian our findings may not be generalizible to other ethnic groups.

The strengths of this study are its prospective design, and the amount of obtained variables. Although multiple comparisons may potentiate the significance of multicollinearity phenomena in multivariate regression analysis, the variance inflation factor in all models presented in Tables 4 and 5 was less than 1.3 , indicating that the amount of multicollinearity was not significant.

\section{Conclusions}

The present study of older persons with hip fracture demonstrates that biochemical parameters of liver function even within its normal range in the majority of patients are relevant to comorbidities and outcomes, documents the regulatory role of adiponecin (but not leptin or resistin) as an independent contributor to GGT activity, and shows that serum GGT (>30 IU/L) and albumin ( $<33 \mathrm{~g} / \mathrm{L}$ ) levels on admission may be helpful in predicting prolonged hospital stay and in-hospital death, respectively.

\section{Authors' contributions}

Both LF and AF were involved in the design of the study, data collection and analyses, manuscript preparation and review, WS performed statistical analysis, PS was involved in drafting and review of the manuscript. All authors approved the final version of the article, including the authorship list.

\section{Conflicts of interest}

The authors report no conflicts of interest in this work.

\section{References}

1. Schmucker DL. Age-related changes in liver structure and function: Implications for disease ? Exp Gerontol. 2005;40:650-9.

2. Le Couteur DG, Warren A, Cogger VC, et al. Old age and the hepatic sinusoid. Anat Rec (Hoboken). 2008;291:672-83.

3. Gan L, Chitturi S, Farrell GC. Mechanisms and implications of age-related changes in the liver: nonalcoholic Fatty liver disease in the elderly. Curr Gerontol Geriatr Res. 2011;2011:831536.

4. Cogger VC, Svistounov D, Warren A, et al. Liver Aging and Pseudocapillarization in a Werner Syndrome Mouse Model. J Gerontol A Biol Sci Med Sci. 2013.

5. Stojakovic T, Scharnagl H, Trauner $M$, et al. Serum gamma-glutamyl transferase and mortality in persons undergoing coronary angiography-The Ludwigshafen Risk and Cardiovascular Health Study. Atherosclerosis. 2010;208:564-71.

6. Elinav E, Ben-Dov IZ, Ackerman E, et al. Correlation between serum alanine aminotransferase activity and age: an inverted $U$ curve pattern. Am J Gastroenterol. 2005;100:2201-4.

7. Elinav E, Ackerman Z, Maaravi Y, et al. Low alanine aminotransferase activity in older people is associated with greater long-term mortality. J Am Geriatr Soc. 2006;54:1719-24.

8. Le Couteur DG, Blyth FM, Creasey HM, et al. The association of alanine transaminase with aging, frailty, and mortality. J Gerontol A Biol Sci Med Sci. 2010;65:712-7.

9. Dong $\mathrm{MH}$, Bettencourt R, Barrett-Connor E, et al. Alanine aminotransferase decreases with age: the Rancho Bernardo Study. PLoS One. 2010;5:e14254.

10. Dong $\mathrm{MH}$, Bettencourt $\mathrm{R}$, Brenner $\mathrm{DA}$, et al. Serum levels of alanine aminotransferase decrease with age in longitudinal analysis. Clin Gastroenterol Hepatol. 2012;10:285-90 e1.

11. Sheedfar F, Di Biase S, Koonen D, et al. Liver diseases and aging: friends or foes? Aging Cell. 2013;12:950-4.

12. Ruhl CE, Everhart JE. Upper limits of normal for alanine aminotransferase activity in the United States population. Hepatology. 2012;55:447-54.

13. Ford I, Mooijaart SP, Lloyd S, et al. The inverse relationship between alanine aminotransferase in the normal range and adverse cardiovascular and non-cardiovascular outcomes. Int J Epidemiol. 2011;40:1530-8.

14. Koehler EM, Sanna D, Hansen BE, et al. Serum liver enzymes are associated with all-cause mortality in an elderly population. Liver Int. 2014;34:296-304.

15. Liu Z, Ning H, Que S, et al. Complex association between alanine aminotransferase activity and mortality in general population: a systematic review and meta-analysis of prospective studies. PLoS One. 2014;9:e91410.

16. Yun KE, Shin CY, Yoon YS, et al. Elevated alanine aminotransferase levels predict mortality from cardiovascular disease and diabetes in Koreans. Atherosclerosis. 2009;205:533-7. 
17. Fleming KM, West J, Aithal GP, et al. Abnormal liver tests in people aged 75 and above: prevalence and association with mortality. Aliment Pharmacol Ther. 2011;34:324-34.

18. Loomba R, Doycheva I, Bettencourt R, et al. Serum gamma-glutamyltranspeptidase predicts all-cause, cardiovascular and liver mortality in older adults. J Clin Exp Hepatol. 2013;3:4-11.

19. Fraser $A$, Thinggaard $M$, Christensen $K$, et al. Alanine aminotransferase, gamma-glutamyltransferase (GGT) and all-cause mortality: results from a population-based Danish twins study alanine aminotransferase, GGT and mortality in elderly twins. Liver Int. 2009;29:1494-9.

20. Kunutsor SK, Apekey TA, Seddoh D, et al. Liver enzymes and risk of all-cause mortality in general populations: a systematic review and meta-analysis. Int J Epidemiol. 2014;43:187-201.

21. Lee DS, Evans JC, Robins SJ, et al. Gamma glutamyl transferase and metabolic syndrome, cardiovascular disease, and mortality risk: the Framingham Heart Study. Arterioscler Thromb Vasc Biol. 2007;27:127-33.

22. Wannamethee SG, Welsh $\mathrm{P}$, Whincup $\mathrm{PH}$, et al. High adiponectin and increased risk of cardiovascular disease and mortality in asymptomatic older men: does NT-proBNP help to explain this association? Eur J Cardiovasc Prev Rehabil. 2011;18:65-71.

23. Ruttmann E, Brant LJ, Concin H, et al. Gamma-glutamyltransferase as a risk factor for cardiovascular disease mortality: an epidemiological investigation in a cohort of 163,944 Austrian adults. Circulation. 2005;112:2130-7.

24. Strasak AM, Kelleher CC, Klenk J, et al. Longitudinal change in serum gamma-glutamyltransferase and cardiovascular disease mortality: a prospective population-based study in 76,113 Austrian adults. Arterioscler Thromb Vasc Biol. 2008;28:1857-65.

25. Fraser A, Harris $\mathrm{R}$, Sattar $\mathrm{N}$, et al. Alanine aminotransferase, gamma-glutamyltransferase, and incident diabetes: the British Women's Heart and Health Study and meta-analysis. Diabetes Care. 2009;32:741-50.

26. Mason JE, Starke RD, Van Kirk JE. Gamma-glutamyl transferase: a novel cardiovascular risk biomarker. Prev Cardiol. 2010;13:36-41.

27. Targher G. Elevated serum gamma-glutamyltransferase activity is associated with increased risk of mortality, incident type 2 diabetes, cardiovascular events, chronic kidney disease and cancer - a narrative review. Clin Chem Lab Med. 2010;48:147-57.

28. Kengne AP, Czernichow S, Stamatakis E, et al. Gamma-glutamyltransferase and risk of cardiovascular disease mortality in people with and without diabetes: pooling of three British Health Surveys. J Hepatol. 2012;57:1083-9.

29. Du G, Song Z, Zhang Q. Gamma-glutamyltransferase is associated with cardiovascular and all-cause mortality: a meta-analysis of prospective cohort studies. Prev Med. 2013;57:31-7.

30. Whitfield JB. Gamma glutamyl transferase. Crit Rev Clin Lab Sci 2001;38:263-355

31. Kim DJ, Noh JH, Cho NH, et al. Serum gamma-glutamyltransferase within its normal concentration range is related to the presence of diabetes and cardiovascular risk factors. Diabet Med. 2005;22:1134-40.

32. Fraser A, Harris R, Sattar N, et al. Gamma-glutamyltransferase is associated with incident vascular events independently of alcohol intake: analysis of the British Women's Heart and Health Study and Meta-Analysis. Arterioscler Thromb Vasc Biol. 2007;27:2729-35.

33. Wannamethee SG, Lennon L, Shaper AG. The value of gamma-glutamyltransferase in cardiovascular risk prediction in men without diagnosed cardiovascular disease or diabetes. Atherosclerosis. 2008;201:168-75.

34. Monami M, Bardini G, Lamanna C, et al. Liver enzymes and risk of diabetes and cardiovascular disease: results of the Firenze Bagno a Ripoli (FIBAR) study. Metabolism. 2008;57:387-92.

35. Olynyk JK, Knuiman MW, Divitini ML, et al. Serum alanine aminotransferase, metabolic syndrome, and cardiovascular disease in an Australian population. Am J Gastroenterol. 2009;104:1715-22.

36. Ghouri N, Preiss D, Sattar N. Liver enzymes, nonalcoholic fatty liver disease, and incident cardiovascular disease: a narrative review and clinical perspective of prospective data. Hepatology. 2010;52:1156-61.

37. Van Hemelrijck M, Jassem W, Walldius G, et al. Gamma-glutamyltransferase and risk of cancer in a cohort of 545,460 persons - the Swedish AMORIS study. Eur J Cancer. 2011;47:2033-41.

38. Liu CF, Gu YT, Wang HY, et al. Gamma-glutamyltransferase level and risk of hypertension: a systematic review and meta-analysis. PLoS One. 2012;7:e48878.

39. Liu CF, Zhou WN, Fang NY. Gamma-glutamyltransferase levels and risk of metabolic syndrome: a meta-analysis of prospective cohort studies. Int J Clin Pract. 2012;66:692-8.

40. Liu Z, Que S, Ning $H$, et al. Elevated alanine aminotransferase is strongly associated with incident metabolic syndrome: a meta-analysis of prospective studies. PLoS One. 2013;8:e80596.

41. Samsky MD, Patel CB, DeWald TA, et al. Cardiohepatic interactions in heart failure: an overview and clinical implications. J Am Coll Cardiol. 2013;61:2397-405.

42. Bradley R, Fitzpatrick AL, Jenny NS, et al. Associations between total serum GGT activity and metabolic risk: MESA. Biomark Med. 2013;7:709-21.

43. Bradley RD, Fitzpatrick AL, Jacobs DR, Jr., et al. Associations between gamma-glutamyltransferase (GGT) and biomarkers of atherosclerosis: the multi-ethnic study of atherosclerosis (MESA). Atherosclerosis. 2014;233:387-93.
44. Kunutsor SK, Seddoh D. Alanine aminotransferase and risk of the metabolic syndrome: a linear dose-response relationship. PLoS One. 2014;9:e96068

45. Lee $\mathrm{DH}, \mathrm{Ha} \mathrm{MH}, \mathrm{Kim} \mathrm{JH}$, et al. Gamma-glutamyltransferase and diabetes--a 4 year follow-up study. Diabetologia. 2003:46:359-64.

46. Emdin M, Passino C, Michelassi C, et al. Additive prognostic value of gamma-glutamyltransferase in coronary artery disease. Int $\mathrm{J}$ Cardiol. 2009;136:80-5.

47. Franzini M, Fornaciari I, Rong J, et al. Correlates and reference limits of plasma gamma-glutamyltransferase fractions from the Framingham Heart Study. Clin Chim Acta. 2013;417:19-25.

48. Nuti M, Spontoni P, Grigoratos C, et al. Lack of a relationship between circulating gamma-glutamyltransferase levels and carotid intima media thickness in hypertensive and diabetic patients. Vasc Health Risk Manag. 2012;8:275-81.

49. Kazemi-Shirazi L, Endler G, Winkler S, et al. Gamma glutamyltransferase and long-term survival: is it just the liver? Clin Chem. 2007;53:940-6.

50. Middelberg RP, Benyamin B, de Moor $\mathrm{MH}$, et al. Loci affecting gamma-glutamyl transferase in adults and adolescents show age $\times$ SNP interaction and cardiometabolic disease associations. Hum Mol Genet. 2012;21:446-55.

51. Rouillard S, Lane NE. Hepatic osteodystrophy. Hepatology 2001;33:301-7.

52. Leslie WD, Bernstein CN, Leboff MS, et al. AGA technical review on osteoporosis in hepatic disorders. Gastroenterology. 2003;125:941-66.

53. Schiefke I, Fach A, Wiedmann M, et al. Reduced bone mineral density and altered bone turnover markers in patients with non-cirrhotic chronic hepatitis B or C infection. World J Gastroenterol. 2005;11:1843-7.

54. Collier J. Bone disorders in chronic liver disease. Hepatology. 2007;46:1271-8.

55. Lopez-Larramona G, Lucendo AJ, Gonzalez-Castillo S, et al. Hepatic osteodystrophy: An important matter for consideration in chronic liver disease. World J Hepatol. 2011;3:300-7.

56. Luxon BA. Bone disorders in chronic liver diseases. Curr Gastroenterol Rep. 2011;13:40-8

57. Yadav A, Carey EJ. Osteoporosis in chronic liver disease. Nutr Clin Pract. 2013;28:52-64

58. Sanchez AJ, Aranda-Michel J. Liver disease and osteoporosis. Nutr Clin Pract. 2006;21:273-8.

59. Lobstein S, Kaiser T, Liebert U, et al. Prevalence, aetiology and associated co-morbidities of elevated aminotransferases in a german cohort of orthopaedic surgery patients. Z Gastroenterol. 2008;46:415-20.

60. Talsnes O, Hjelmstedt F, Dahl OE, et al. Biochemical lung, liver and kidney markers and early death among elderly following hip fracture. Arch Orthop Trauma Surg. 2012;132:1753-8.

61. Pimlott BJ, Jones CA, Beaupre LA, et al. Prognostic impact of pre-operative albumin on short-term mortality and complications in patients with hip fracture. Arch Gerontol Geriatr. 2011:53:90-4

62. Laulund AS, Lauritzen JB, Duus BR, et al. Routine blood tests as predictors of mortality in hip fracture patients. Injury 2012;43:1014-20.

63. Carpintero $\mathrm{P}$, Lopez $\mathrm{P}$, Leon $\mathrm{F}$, et al. Men with hip fractures have poorer nutritional status and survival than women: a prospective study of 165 patients. Acta Orthop. 2005;76:331-5

64. Hershkovitz A, Polatov I, Beloosesky Y, et al. Factors affecting mortality of frail hip-fractured elderly patients. Arch Gerontol Geriatr. 2010;51:113-6.

65. Koval KJ, Maurer SG, Su ET, et al. The effects of nutritional status on outcome after hip fracture. J Orthop Trauma. 1999;13:164-9.

66. Pioli G, Barone A, Giusti A, et al. Predictors of mortality after hip fracture: results from 1-year follow-up. Aging Clin Exp Res. 2006;18:381-7.

67. Hu F, Jiang C, Shen J, et al. Preoperative predictors for mortality following hip fracture surgery: a systematic review and meta-analysis. Injury. 2012;43:676-85.

68. Ozturk A, Ozkan Y, Akgoz S, et al. The risk factors for mortality in elderly patients with hip fractures: postoperative one-year results. Singapore Med J. 2010;51:137-43.

69. Lee HP, Chang YY, Jean YH, et al. Importance of serum albumin level in the preoperative tests conducted in elderly patients with hip fracture. Injury. 2009;40:756-9.

70. Kamada Y, Takehara T, Hayashi N. Adipocytokines and liver disease. J Gastroenterol. 2008;43:811-22.

71. Clark JM, Brancati FL, Diehl AM. The prevalence and etiology of elevated aminotransferase levels in the United States. Am J Gastroenterol. 2003:98:960-7

72. Pendino GM, Mariano A, Surace P, et al. Prevalence and etiology of altered liver tests: a population-based survey in a Mediterranean town. Hepatology. 2005;41:1151-9.

73. Ioannou GN, Boyko EJ, Lee SP. The prevalence and predictors of elevated serum aminotransferase activity in the United States in 1999-2002. Am J Gastroenterol. 2006;101:76-82.

74. Papatheodoridis GV, Goulis J, Christodoulou D, et al. High prevalence of elevated liver enzymes in blood donors: associations with male gender and central adiposity. Eur J Gastroenterol Hepatol. 2007:19:281-7.

75. Zhang H, He SM, Sun J, et al. Prevalence and etiology of abnormal liver tests in an adult population in Jilin, China. Int J Med Sci. 2011;8:254-62.

76. Mohamadnejad M, Pourshams A, Malekzadeh R, et al. Healthy ranges of serum alanine aminotransferase levels in Iranian blood donors. World J Gastroenterol. 2003;9:2322-4. 
77. Meisinger C, Doring A, Schneider A, et al. Serum gamma-glutamyltransferase is a predictor of incident coronary events in apparently healthy men from the general population. Atherosclerosis. 2006;189:297-302.

78. Liangpunsakul S, Chalasani N. Unexplained elevations in alanine aminotransferase in individuals with the metabolic syndrome: results from the third National Health and Nutrition Survey (NHANES III). Am J Med Sci. 2005;329:111-6.

79. Patt CH, Yoo HY, Dibadj K, et al. Prevalence of transaminase abnormalities in asymptomatic, healthy subjects participating in an executive health-screening program. Dig Dis Sci. 2003;48:797-801.

80. Liu CM, Tung TH, Liu JH, et al. A community-based epidemiological study of elevated serum alanine aminotransferase levels in Kinmen, Taiwan. World J Gastroenterol. 2005;11:1616-22.

81. Ruhl CE, Everhart JE. Relation of elevated serum alanine aminotransferase activity with iron and antioxidant levels in the United States. Gastroenterology 2003;124:1821-9.

82. Adamczak M, Rzepka E, Chudek J, et al. Ageing and plasma adiponectin concentration in apparently healthy males and females. Clin Endocrinol (Oxf). 2005;62:114-8.

83. Atzmon G, Pollin TI, Crandall J, et al. Adiponectin levels and genotype: a potential regulator of life span in humans. J Gerontol A Biol Sci Med Sci. 2008;63:447-53.

84. Kizer JR, Arnold AM, Strotmeyer ES, et al. Change in circulating adiponectin in advanced old age: determinants and impact on physical function and mortality. The Cardiovascular Health Study All Stars Study. J Gerontol A Biol Sci Med Sci. 2010;65:1208-14.

85. Nakatsuji H, Kishida K, Kobayashi H, et al. Correlation of circulating C1q and C1q-binding adiponectin concentrations with aging in males: a preliminary report. Diabetol Metab Syndr. 2013;5:17.

86. Obata Y, Yamada Y, Takahi Y, et al. Relationship between serum adiponectin levels and age in healthy subjects and patients with type 2 diabetes. Clin Endocrinol (Oxf). 2013;79:204-10.

87. Marques-Vidal P, Bochud M, Paccaud F, et al. Distribution of plasma levels of adiponectin and leptin in an adult Caucasian population. Clin Endocrinol (Oxf). 2010;72:38-46

88. Schautz B, Later W, Heller M, et al. Impact of age on leptin and adiponectin independent of adiposity. Br J Nutr. 2012;108:363-70.

89. Lips P. Vitamin D deficiency and secondary hyperparathyroidism in the elderly: consequences for bone loss and fractures and therapeutic implications. Endocr Rev. 2001;22:477-501.

90. Kamycheva E, Sundsfjord J, Jorde R. Serum parathyroid hormone levels predict coronary heart disease: the Tromso Study. Eur J Cardiovasc Prev Rehabil. 2004;11:69-74.

91. Giusti A, Barone A, Razzano M, et al. High prevalence of secondary hyperparathyroidism due to hypovitaminosis D in hospitalized elderly with and without hip fracture. J Endocrinol Invest. 2006;29:809-13.

92. Rejnmark L, Vestergaard P, Heickendorff L, et al. Determinants of plasma PTH and their implication for defining a reference interval. Clin Endocrinol (Oxf). 2011;74:37-43.

93. Puntus T, Schneider B, Meran J, et al. Influence of age and gender on associations of body mass index with bone mineral density, bone turnover markers and circulating calcium-regulating and bone-active sex hormones. Bone. 2011;49:824-9.

94. Di Monaco M, Castiglioni C, Vallero F, et al. Parathyroid-hormone variance is only marginally explained by a panel of determinants: a cross-sectional study of 909 hip-fracture patients. J Bone Miner Metab. 2013.

95. Touvier M, Deschasaux M, Montourcy M, et al. Interpretation of plasma PTH concentrations according to 25OHD status, gender, age, weight status, and calcium intake: importance of the reference values. J Clin Endocrinol Metab. 2014;99:1196-203.

96. Park JS, Kang S, Ahn CW, et al. Relationships between serum uric acid, adiponectin and arterial stiffness in postmenopausal women. Maturitas. 2012;73:344-8.

97. Aksakal E, Tanboga IH, Kurt M, et al. The relation of serum gamma-glutamyl transferase levels with coronary lesion complexity and long-term outcome in patients with stable coronary artery disease. Atherosclerosis. 2012;221:596-601.

98. Dogan A, Icli A, Aksoy F, et al. Gamma-glutamyltransferase in acute coronary syndrome patients without ST elevation and its association with stenotic lesion and cardiac events. Coron Artery Dis. 2012;23:39-44.

99. Niccoli G, Della Bona $R$, Cosentino $N$, et al. Serum levels of gamma-glutamyltransferase and progression of coronary atherosclerosis. Coron Artery Dis. 2013;24:40-7.

100. Korantzopoulos P, Tzimas P, Kalantzi K, et al. Association between serum gamma-glutamyltransferase and acute ischemic nonembolic stroke in elderly subjects. Arch Med Res. 2009;40:582-9.

101. Atar AI, Yilmaz OC, Akin K, et al. Association between gamma-glutamyltransferase and coronary artery calcification. Int J Cardiol. 2013;167:1264-7.

102. Turgut O, Tandogan I. Gamma-glutamyltransferase to determine cardiovascular risk: shifting the paradigm forward. J Atheroscler Thromb. 2011;18:177-81.

103. Jiang S, Jiang D, Tao Y. Role of gamma-glutamyltransferase in cardiovascular diseases. Exp Clin Cardiol. 2013;18:53-6.
104. Onat A, Can G, Ornek E, et al. Serum gamma-glutamyltransferase: independent predictor of risk of diabetes, hypertension, metabolic syndrome, and coronary disease. Obesity (Silver Spring). 2012;20:842-8.

105. Ruhl CE, Everhart JE. Elevated serum alanine aminotransferase and gamma-glutamyltransferase and mortality in the United States population. Gastroenterology. 2009;136:477-85 e11.

106. Fraser A, Ebrahim S, Smith GD, et al. A comparison of associations of alanine aminotransferase and gamma-glutamyltransferase with fasting glucose, fasting insulin, and glycated hemoglobin in women with and without diabetes. Hepatology. 2007;46:158-65.

107. Paolicchi A, Emdin M, Passino C, et al. Beta-lipoprotein- and LDL-associated serum gamma-glutamyltransferase in patients with coronary atherosclerosis. Atherosclerosis. 2006;186:80-5.

108. Kozakova M, Palombo C, Eng MP, et al. Fatty liver index, gamma-glutamyltransferase, and early carotid plaques. Hepatology. 2012;55:1406-15.

109. Shin JY, Chang SJ, Shin YG, et al. Elevated serum gamma-glutamyltransferase levels are independently associated with insulin resistance in non-diabetic subjects. Diabetes Res Clin Pract. 2009;84:152-7.

110. Kew MC. Serum aminotransferase concentration as evidence of hepatocellular damage. Lancet. 2000;355:591-2.

111. Djousse L, Rothman KJ, Cupples LA, et al. Effect of serum albumin and bilirubin on the risk of myocardial infarction (the Framingham Offspring Study). Am J Cardiol. 2003;91:485-8.

112. Turfan M, Duran M, Poyraz F, et al. Inverse relationship between serum total bilirubin levels and severity of disease in patients with stable coronary artery disease. Coron Artery Dis. 2013;24:29-32

113. Erdogan D, Gullu H, Yildirim E, et al. Low serum bilirubin levels are independently and inversely related to impaired flow-mediated vasodilation and increased carotid intima-media thickness in both men and women. Atherosclerosis. 2006;184:431-7.

114. Yang XF, Chen YZ, Su JL, et al. Relationship between serum bilirubin and carotid atherosclerosis in hypertensive patients. Intern Med. 2009;48:1595-9.

115. Perlstein TS, Pande RL, Beckman JA, et al. Serum total bilirubin level and prevalent lower-extremity peripheral arterial disease: National Health and Nutrition Examination Survey (NHANES) 1999 to 2004. Arterioscler Thromb Vasc Biol. 2008;28:166-72.

116. Ong KL, Allison MA, Cheung BM, et al. The Relationship between Total Bilirubin Levels and Total Mortality in Older Adults: The United States National Health and Nutrition Examination Survey (NHANES) 1999-2004. PLoS One. 2014:9:e94479.

117. Gullu H, Erdogan D, Tok D, et al. High serum bilirubin concentrations preserve coronary flow reserve and coronary microvascular functions. Arterioscler Thromb Vasc Biol. 2005;25:2289-94.

118. Horsfall LJ, Nazareth I, Petersen I. Cardiovascular events as a function of serum bilirubin levels in a large, statin-treated cohort. Circulation. 2012;126:2556-64.

119. Perlstein TS, Pande RL, Creager MA, et al. Serum total bilirubin level, prevalent stroke, and stroke outcomes: NHANES 1999-2004. Am J Med. 2008;121:781-788 e1.

120. Kimm H, Yun JE, Jo J, et al. Low serum bilirubin level as an independent predictor of stroke incidence: a prospective study in Korean men and women. Stroke. 2009;40:3422-7.

121. Oda E, Kawai R. A possible cross-sectional association of serum total bilirubin with coronary heart disease and stroke in a Japanese health screening population. Heart Vessels. 2012;27:29-36.

122. Vitek L, Jirsa M, Brodanova M, et al. Gilbert syndrome and ischemic heart disease: a protective effect of elevated bilirubin levels. Atherosclerosis. 2002;160:449-56.

123. Kubo SH, Walter BA, John DH, et al. Liver function abnormalities in chronic heart failure. Influence of systemic hemodynamics. Arch Intern Med. 1987:147:1227-30.

124. Allen LA, Felker GM, Pocock S, et al. Liver function abnormalities and outcome in patients with chronic heart failure: data from the Candesartan in Heart Failure: Assessment of Reduction in Mortality and Morbidity (CHARM) program. Eur J Heart Fail. 2009;11:170-7.

125. Szygula-Jurkiewicz B, Wojnicz R, Lekston A, et al. [Effect of elevated bilirubin levels on the long-term outcome in patients with chronic heart failure due to hypertension]. Pol Arch Med Wewn. 2007;117:227-33.

126. Valentova M, von Haehling S, Krause C, et al. Cardiac cachexia is associated with right ventricular failure and liver dysfunction. Int J Cardiol. 2013;169:219-24

127. Okuhara K, Kisaka T, Ozono R, et al. Change in bilirubin level following acute myocardial infarction is an index for heme oxygenase activation. South Med J. 2010;103:876-81.

128. Gul M, Uyarel $H$, Ergelen $M$, et al. Prognostic value of total bilirubin in patients with ST-segment elevation acute myocardial infarction undergoing primary coronary intervention. Am J Cardiol. 2013;111:166-71.

129. Nishi H, Sakaguchi T, Miyagawa S, et al. Frequency, risk factors and prognosis of postoperative hyperbilirubinemia after heart valve surgery. Cardiology. 2012;122:12-9.

130. Hostmark AT, Tomten SE, Berg JE. Serum albumin and blood pressure: a population-based, cross-sectional study. J Hypertens. 2005;23:725-30. 
131. Danesh J, Collins R, Appleby P, et al. Association of fibrinogen, C-reactive protein, albumin, or leukocyte count with coronary heart disease: meta-analyses of prospective studies. JAMA. 1998;279:1477-82

132. Ishizaka N, Ishizaka $\mathrm{Y}$, Nagai R, et al. Association between serum albumin, carotid atherosclerosis, and metabolic syndrome in Japanese individuals. Atherosclerosis. 2007;193:373-9.

133. Kadono M, Hasegawa G, Shigeta $M$, et al. Serum albumin levels predict vascular dysfunction with paradoxical pathogenesis in healthy individuals. Atherosclerosis. 2010;209:266-70.

134. Kuller LH, Tracy RP, Shaten J, et al. Relation of C-reactive protein and coronary heart disease in the MRFIT nested case-control study. Multiple Risk Factor Intervention Trial. Am J Epidemiol. 1996;144:537-47.

135. Weijenberg MP, Feskens EJ, Souverijn JH, et al. Serum albumin, coronary heart disease risk, and mortality in an elderly cohort. Epidemiology. 1997;8:87-92.

136. Bae JC, Seo SH, Hur KY, et al. Association between Serum Albumin, Insulin Resistance, and Incident Diabetes in Nondiabetic Subjects. Endocrinol Metab (Seoul). 2013;28:26-32.

137. Luk JK, Chiu PK, Tam S, et al. Relationship between admission albumin levels and rehabilitation outcomes in older patients. Arch Gerontol Geriatr. 2011;53:84-9.

138. Kang $\mathrm{YH}$, Min $\mathrm{HK}$, Son $\mathrm{SM}$, et al. The association of serum gamma glutamyltransferase with components of the metabolic syndrome in the Korean adults. Diabetes Res Clin Pract. 2007;77:306-13.

139. Lee DH, Lim JS, Yang JH, et al. Serum gamma-glutamyltransferase within its normal range predicts a chronic elevation of alanine aminotransferase: a four year follow-up study. Free Radic Res. 2005;39:589-93.

140. Webber M, Krishnan A, Thomas NG, et al. Association between serum alkaline phosphatase and C-reactive protein in the United States National Health and Nutrition Examination Survey 2005-2006. Clin Chem Lab Med. 2010;48:167-73.

141. Wang Z, McMonagle C, Yoshimitsu S, et al. No effect modification of serum bilirubin or coffee consumption on the association of gamma-glutamyltransferase with glycated hemoglobin in a cross-sectional study of Japanese men and women. BMC Endocr Disord. 2012;12:24.

142. Bahr MJ, Ockenga J, Boker $\mathrm{KH}$, et al. Elevated resistin levels in cirrhosis are associated with the proinflammatory state and altered hepatic glucose metabolism but not with insulin resistance. Am J Physiol Endocrinol Metab. 2006;291:E199-206.

143. Marra F, Bertolani C. Adipokines in liver diseases. Hepatology. 2009;50:957-69.

144. Polyzos SA, Toulis KA, Goulis DG, et al. Serum total adiponectin in nonalcoholic fatty liver disease: a systematic review and meta-analysis. Metabolism. 2011;60:313-26.

145. Moschen AR, Wieser V, Tilg H. Adiponectin: key player in the adipose tissue-liver crosstalk. Curr Med Chem. 2012;19:5467-73.

146. Li Y, Ding L, Hassan W, et al. Adipokines and hepatic insulin resistance. J Diabetes Res. 2013;2013:170532

147. Silva TE, Colombo G, Schiavon LL. Adiponectin: A multitasking player in the field of liver diseases. Diabetes Metab. 2014;40:95-107.

148. Elias-Miro M, Massip-Salcedo M, Jimenez-Castro M, et al. Does adiponectin benefit steatotic liver transplantation? Liver Transpl. 2011;17:993-1004.

149. Kakizaki S, Sohara N, Yamazaki Y, et al. Elevated plasma resistin concentrations in patients with liver cirrhosis. J Gastroenterol Hepatol. 2008;23:73-7.

150. Finelli C, Tarantino G. What is the role of adiponectin in obesity related non-alcoholic fatty liver disease? World J Gastroenterol. 2013;19:802-12.

151. Montonen J, Drogan D, Joost HG, et al. Estimation of the contribution of biomarkers of different metabolic pathways to risk of type 2 diabetes. Eur J Epidemiol. 2011;26:29-38.

152. Marques-Vidal P, Schmid R, Bochud M, et al. Adipocytokines, hepatic and inflammatory biomarkers and incidence of type 2 diabetes. the CoLaus study. PLoS One. 2012;7:e51768.

153. Kamada $\mathrm{Y}$, Nakamura $\mathrm{T}$, Funahashi $\mathrm{T}$, et al. Visceral obesity and hypoadiponectinemia are significant determinants of hepatic dysfunction: An epidemiologic study of 3827 Japanese subjects. J Clin Gastroenterol. 2009;43:995-1000.

154. Targher G, Bertolini L, Scala L, et al. Decreased plasma adiponectin concentrations are closely associated with nonalcoholic hepatic steatosis in obese individuals. Clin Endocrinol (Oxf). 2004;61:700-3.

155. Aygun C, Senturk O, Hulagu S, et al. Serum levels of hepatoprotective peptide adiponectin in non-alcoholic fatty liver disease. Eur J Gastroenterol Hepatol. 2006;18:175-80.

156. $\mathrm{Xu} \mathrm{A}$, Wang $\mathrm{Y}$, Keshaw $\mathrm{H}$, et al. The fat-derived hormone adiponectin alleviates alcoholic and nonalcoholic fatty liver diseases in mice. J Clin Invest. 2003;112:91-100.

157. Lopez-Bermejo A, Botas P, Funahashi T, et al. Adiponectin, hepatocellular dysfunction and insulin sensitivity. Clin Endocrinol (Oxf). 2004;60:256-63.

158. Sargin H, Sargin M, Gozu H, et al. Is adiponectin level a predictor of nonalcoholic fatty liver disease in nondiabetic male patients? World J Gastroenterol. 2005;11:5874-7.

159. Kim JA, Kim SM, Yoon D. The relationship between gamma-glutamyltransferase and adiponectin in nonalcoholic women. Metabolism. 2007:56:578-82.

160. Yokoyama $\mathrm{H}$, Hirose $\mathrm{H}$, Ohgo $\mathrm{H}$, et al. Inverse association between serum adiponectin level and transaminase activities in Japanese male workers. J Hepatol. 2004;41:19-24.
161. Kazumi T, Kawaguchi A, Hirano $\mathrm{T}$, et al Serum alanine aminotransferase is associated with serum adiponectin, C-reactive protein and apolipoprotein B in young healthy men. Horm Metab Res. 2006;38:119-24.

162. de Luis DA, Sagrado MG, Conde R, et al. Relation of visfatin to cardiovascular risk factors and adipocytokines in patients with impaired fasting glucose. Nutrition. 2013;29:1300-3.

163. Tietge UJ, Boker KH, Manns MP, et al. Elevated circulating adiponectin levels in liver cirrhosis are associated with reduced liver function and altered hepatic hemodynamics. Am J Physiol Endocrinol Metab. 2004;287:E82-9.

164. Salman TA, Allam N, Azab GI, et al. Study of adiponectin in chronic liver disease and cholestasis. Hepatol Int. 2010;4:767-74.

165. Balmer ML, Joneli J, Schoepfer A, et al. Significance of serum adiponectin levels in patients with chronic liver disease. Clin Sci (Lond). 2010;119:431-6.

166. Pagano C, Soardo G, Esposito W, et al. Plasma adiponectin is decreased in nonalcoholic fatty liver disease. Eur J Endocrinol. 2005;152:113-8.

167. Whitehead JP, Richards AA, Hickman IJ, et al. Adiponectin--a key adipokine in the metabolic syndrome. Diabetes Obes Metab. 2006;8:264-80.

168. Uetani E, Tabara Y, Igase M, et al. Liver enzyme and adipocytokine profiles are synergistically associated with insulin resistance: the J-SHIPP study. J Atheroscler Thromb. 2012;19:577-84.

169. Cook JR, Semple RK. Hypoadiponectinemia--cause or consequence of human "insulin resistance"? J Clin Endocrinol Metab. 2010;95:1544-54.

170. Kizer JR, Benkeser D, Arnold AM, et al. Associations of total and high-molecular-weight adiponectin with all-cause and cardiovascular mortality in older persons: the Cardiovascular Health Study. Circulation. 2012;126:2951-61.

171. Kizer JR, Benkeser D, Arnold AM, et al. Total and high-molecular-weight adiponectin and risk of coronary heart disease and ischemic stroke in older adults. J Clin Endocrinol Metab. 2013;98:255-63.

172. Connelly PW, Ramesh Prasad GV. Adiponectin in renal disease--a review of the evidence as a risk factor for cardiovascular and all-cause mortality. Crit Rev Clin Lab Sci. 2012:49:218-31.

173. Teoh H, Strauss MH, Szmitko PE, et al. Adiponectin and myocardial infarction: A paradox or a paradigm? Eur Heart J. 2006;27:2266-8.

174. Kistorp C, Faber J, Galatius S, et al. Plasma adiponectin, body mass index, and mortality in patients with chronic heart failure. Circulation. 2005;112:1756-62.

175. Teoh H, Quan A, Bang KW, et al. Adiponectin deficiency promotes endothelial activation and profoundly exacerbates sepsis-related mortality. Am J Physiol Endocrinol Metab. 2008;295:E658-64.

176. Uji Y, Yamamoto H, Tsuchihashi H, et al. Adiponectin deficiency is associated with severe polymicrobial sepsis, high inflammatory cytokine levels, and high mortality. Surgery. 2009;145:550-7.

177. Dembinski R. Adiponectin in critically ill patients: more questions than answers? Crit Care Med. 2010;38:2415-6.

178. Dieplinger B, Haltmayer M, Poelz W, et al. Value of adiponectin as predictor of 5-year all-cause mortality in patients with symptomatic peripheral arterial disease: results from the Linz Peripheral Arterial Disease (LIPAD) study. Clin Chim Acta. 2009:408:87-91.

179. Schnabel R, Messow CM, Lubos E, et al. Association of adiponectin with adverse outcome in coronary artery disease patients: results from the AtheroGene study. Eur Heart J. 2008;29:649-57.

180. Urbonaviciene $G$, Frystyk J, Flyvbjerg A, et al. Association of serum adiponectin with risk for cardiovascular events in patients with peripheral arterial disease. Atherosclerosis. 2010;210:619-24.

181. Sood A, Qualls C, Schuyler M. Leptin, adiponectin, and asthma: findings from a population-based cohort study. Ann Allergy Asthma Immunol. 2010;104:355; author reply 355-6.

182. Beige J, Heipmann K, Stumvoll M, et al. Paradoxical role for adiponectin in chronic renal diseases? An example of reverse epidemiology. Expert Opin Ther Targets. 2009;13:163-73.

183. Kishida K, Funahashi T, Shimomura I. Adiponectin as a routine clinical biomarker. Best Pract Res Clin Endocrinol Metab. 2014;28:119-30.

184. Sattar N, Nelson SM. Adiponectin, diabetes, and coronary heart disease in older persons: unraveling the paradox. J Clin Endocrinol Metab. 2008;93:3299-301.

185. Karas MG, Benkeser D, Arnold AM, et al. Relations of plasma total and high-molecular-weight adiponectin to new-onset heart failure in adults $>/=65$ years of age (from the Cardiovascular Health study). Am J Cardiol. 2014;113:328-34.

186. Kizer JR. A tangled threesome: adiponectin, insulin sensitivity, and adiposity: can Mendelian randomization sort out causality? Diabetes. 2013;62:1007-9.

187. Arai Y, Takayama M, Abe $\mathrm{Y}$, et al. Adipokines and aging. J Atheroscler Thromb. 2011;18:545-50

188. Bik W, Baranowska-Bik A, Wolinska-Witort E, et al. Assessment of adiponectin and its isoforms in Polish centenarians. Exp Gerontol. 2013;48:401-7.

189. Loncar G, Bozic B, Dimkovic S, et al. Association of increased parathyroid hormone with neuroendocrine activation and endothelial dysfunction in elderly men with heart failure. J Endocrinol Invest. 2011;34:e78-85.

190. Bhadada SK, Bhansali A, Shah VN, et al. Changes in serum leptin and adiponectin concentrations and insulin resistance after curative parathyroidectomy in moderate to severe primary hyperparathyroidism. Singapore Med J. 2011;52:890-3. 
191. Delfini E, Petramala L, Caliumi C, et al. Circulating leptin and adiponectin levels in patients with primary hyperparathyroidism. Metabolism. 2007;56:30-6.

192. Bollerslev J, Rosen T, Mollerup CL, et al. Effect of surgery on cardiovascular risk factors in mild primary hyperparathyroidism. J Clin Endocrinol Metab. 2009;94:2255-61.

193. de Luis DA, Soto GD, Conde R, et al. Relation of leptin and adiponectin with cardiovascular risk factors, intact parathormone, and vitamin D levels in patients with primary hyperparathyroidism. J Clin Lab Anal. 2012;26:398-402.

194. Villanueva I, Alva-Sanchez C, Pacheco-Rosado J. The role of thyroid hormones as inductors of oxidative stress and neurodegeneration. Oxid Med Cell Longev. 2013;2013:218145.

195. Harman D. Origin and evolution of the free radical theory of aging: a brief personal history, 1954-2009. Biogerontology. 2009;10:773-81.

196. Jacob KD, Noren Hooten N, Trzeciak AR, et al. Markers of oxidant stress that are clinically relevant in aging and age-related disease. Mech Ageing Dev. 2013;134:139-57.

197. Cencioni C, Spallotta F, Martelli F, et al. Oxidative stress and epigenetic regulation in ageing and age-related diseases. Int J Mol Sci. 2013;14:17643-63.

198. Sohal RS, Orr WC. The redox stress hypothesis of aging. Free Radic Biol Med. 2012;52:539-55.

199. Holmstrom KM, Finkel T. Cellular mechanisms and physiological consequences of redox-dependent signalling. Nat Rev Mol Cell Biol. 2014;15:411-21.

200. Ames BN, Shigenaga MK, Hagen TM. Mitochondrial decay in aging. Biochim Biophys Acta. 1995;1271:165-70.

201. Tian L, Cai Q, Wei H. Alterations of antioxidant enzymes and oxidative damage to macromolecules in different organs of rats during aging. Free Radic Biol Med. 1998;24:1477-84.

202. Martin R, Fitzl G, Mozet C, et al. Effect of age and hypoxia/reoxygenation on mRNA expression of antioxidative enzymes in rat liver and kidneys. Exp Gerontol. 2002;37:1481-7.

203. Pompella A, Visvikis A, Paolicchi A, et al. The changing faces of glutathione, a cellular protagonist. Biochem Pharmacol. 2003;66:1499-503.

204. Lim JS, Yang JH, Chun BY, et al. Is serum gamma-glutamyltransferase inversely associated with serum antioxidants as a marker of oxidative stress? Free Radic Biol Med. 2004;37:1018-23.

205. Lee DH, Blomhoff R, Jacobs DR, Jr. Is serum gamma glutamyltransferase a marker of oxidative stress? Free Radic Res. 2004;38:535-9.

206. Yamada J, Tomiyama H, Yambe M, et al. Elevated serum levels of alanine aminotransferase and gamma glutamyltransferase are markers of inflammation and oxidative stress independent of the metabolic syndrome. Atherosclerosis. 2006;189:198-205.

207. Simao AN, Dichi JB, Barbosa DS, et al. Influence of uric acid and gamma-glutamyltransferase on total antioxidant capacity and oxidative stress in patients with metabolic syndrome. Nutrition. 2008;24:675-81.

208. Enoiu M, Aberkane H, Salazar JF, et al. Evidence for the pro-oxidant effect of gamma-glutamyltranspeptidase-related enzyme. Free Radic Biol Med. 2000;29:825-33.

209. Glass GA, Stark AA. Promotion of glutathione-gamma-glutamyl transpeptidase-dependent lipid peroxidation by copper and ceruloplasmin: the requirement for iron and the effects of antioxidants and antioxidant enzymes. Environ Mol Mutagen. 1997;29:73-80.

210. Drozdz R, Parmentier C, Hachad H, et al. gamma-Glutamyltransferase dependent generation of reactive oxygen species from a glutathione/transferrin system. Free Radic Biol Med. 1998;25:786-92.

211. Roche M, Rondeau P, Singh NR, et al. The antioxidant properties of serum albumin. FEBS Lett. 2008;582:1783-7.

212. Torres MJ, Turell L, Botti H, et al. Modulation of the reactivity of the thiol of human serum albumin and its sulfenic derivative by fatty acids. Arch Biochem Biophys. 2012;521:102-10.

213. Turell L, Radi R, Alvarez B. The thiol pool in human plasma: the central contribution of albumin to redox processes. Free Radic Biol Med. 2013;65:244-53.

214. Baranano DE, Rao M, Ferris CD, et al. Biliverdin reductase: a major physiologic cytoprotectant. Proc Natl Acad Sci U S A. 2002;99:16093-8.

215. Park M, Youn B, Zheng XL, et al. Globular adiponectin, acting via AdipoR1/APPL1, protects H9c2 cells from hypoxia/reoxygenation-induced apoptosis. PLoS One. 2011;6:e19143.

216. Zhang Y, Wang XL, Zhao J, et al. Adiponectin inhibits oxidative/nitrative stress during myocardial ischemia and reperfusion via PKA signaling. Am J Physiol Endocrinol Metab. 2013;305:E1436-43.

217. Furukawa S, Fujita T, Shimabukuro $M$, et al. Increased oxidative stress in obesity and its impact on metabolic syndrome. J Clin Invest. 2004;114:1752-61.

218. Fujita K, Nishizawa H, Funahashi $T$, et al. Systemic oxidative stress is associated with visceral fat accumulation and the metabolic syndrome. Circ J. 2006;70:1437-42

219. Gustafsson S, Lind L, Soderberg S, et al. Oxidative stress and inflammatory markers in relation to circulating levels of adiponectin. Obesity (Silver Spring). 2013;21:1467-73.

220. Matsuda M, Shimomura I. Roles of adiponectin and oxidative stress in obesity-associated metabolic and cardiovascular diseases. Rev Endocr Metab Disord. 2014;15:1-10

221. Buechler C, Wanninger J, Neumeier M. Adiponectin, a key adipokine in obesity related liver diseases. World J Gastroenterol. 2011;17:2801-11.
222. Osto E, Fallo F, Pelizzo MR, et al. Coronary microvascular dysfunction induced by primary hyperparathyroidism is restored after parathyroidectomy. Circulation 2012;126:1031-9.

223. Ellam $\mathrm{T}$, Fotheringham J, Wilkie $\mathrm{ME}$, et al. Bone mineral metabolism parameters and urinary albumin excretion in a representative US population sample. PLoS One. 2014;9:e88388.

224. Wang $\mathrm{CH}, \mathrm{Wu} \mathrm{SB}, \mathrm{Wu} \mathrm{YT}$, et al. Oxidative stress response elicited by mitochondrial dysfunction: implication in the pathophysiology of aging. Exp Biol Med (Maywood). 2013;238:450-60.

225. Ouchi N, Walsh K. A novel role for adiponectin in the regulation of inflammation. Arterioscler Thromb Vasc Biol. 2008;28:1219-21.

226. Symeonidis PD, Clark D. Assessment of malnutrition in hip fracture patients: effects on surgical delay, hospital stay and mortality. Acta Orthop Belg. 2006;72:420-7.

227. O'Daly BJ, Walsh JC, Quinlan JF, et al. Serum albumin and total lymphocyte count as predictors of outcome in hip fractures. Clin Nutr. 2010;29:89-93.

228. Kumar V, Alva A, Akkena S, et al. Are albumin and total lymphocyte count significant and reliable predictors of mortality in fractured neck of femur patients? Eur J Orthop Surg Traumatol. 2013

229. Wright OR, Hickman IJ, Petchey WG, et al. The effect of 25-hydroxyvitamin D on insulin sensitivity in obesity: is it mediated via adiponectin? Can J Physiol Pharmacol. 2013;91:496-501. 